\title{
MIDAS
}

Museus e estudos interdisciplinares

$12 \mid 2020$

Varia

\section{Encenação do Estado Novo na exposição Quinze Anos de Obras Públicas (Lisboa, 1948)}

Staging the Estado Novo in the exhibition Quinze Anos de Obras Públicas

(Fifteen Years of Public Works) (Lisbon, 1948)

\section{Ana Mehnert Pascoal}

\section{OpenEdition}

\section{Journals}

\section{Edição electrónica}

URL: https://journals.openedition.org/midas/2446

DOI: $10.4000 /$ midas. 2446

ISSN: $2182-9543$

\section{Editora:}

Alice Semedo, Paulo Simões Rodrigues, Pedro Casaleiro, Raquel Henriques da Silva, Ana Carvalho

\section{Refêrencia eletrónica}

Ana Mehnert Pascoal, «Encenação do Estado Novo na exposição Quinze Anos de Obras Públicas

(Lisboa, 1948)», MIDAS [Online], 12 | 2020, posto online no dia 15 dezembro 2020, consultado no dia

04 março 2022. URL: http://journals.openedition.org/midas/2446 ; DOI: https://doi.org/10.4000/

midas. 2446

Este documento foi criado de forma automática no dia 4 março 2022.

\section{(c) (†) (ㅇ)}

Midas is licensed under a Creative Commons Attribution-NonCommercial-ShareAlike 3.0 International License 


\title{
Encenação do Estado Novo na exposição Quinze Anos de Obras Públicas (Lisboa, 1948)
}

Staging the Estado Novo in the exhibition Quinze Anos de Obras Públicas

(Fifteen Years of Public Works) (Lisbon, 1948)

\author{
Ana Mehnert Pascoal
}

\section{NOTA DO EDITOR}

Artigo recebido a 28.09.2019

Aprovado para publicação a 29.07.2020

\section{Introdução}

1 Este artigo centra-se na exposição Quinze Anos de Obras Públicas (1932-1947), decorrida em 1948 no Instituto Superior Técnico (IST), em Lisboa, coincidindo com o I Congresso Nacional de Arquitetura e o II Congresso Nacional de Engenharia, num período marcado por tensões políticas.

2 Após a II Guerra Mundial, Portugal encontrava-se diante de um panorama internacional de democratização e de uma crise interna devido à reorganização da oposição. Aparentes alterações no sistema político com as eleições à Assembleia Nacional em 1945, não tiveram repercussões práticas, desencadeando prisões, saneamentos e a ilegalização do Movimento de Unidade Democrática. O aparelho repressivo foi reforçado, reformulando a PIDE como PVDE e mantendo mecanismos de violência preventiva e punitiva (Rosas 1994; Reis 2015). No campo cultural, cite-se o controlo da dissidência através da apreensão de pinturas de artistas politizados na II Exposição Geral de Artes Plásticas, em 1947 (França 1991, 362), ou da proibição de certos arquitetos 
lecionarem nas Escolas de Belas-Artes (Brites 2015, 367). A permanência de António de Oliveira Salazar no poder foi, ainda, subsidiária da manutenção do apoio das Forças Armadas e da Igreja Católica, da estrutura corporativa e do projeto totalitário de inculcação ideológica (Rosas 2013).

3 Nesta altura, fomentaram-se eventos mobilizadores da população, como a celebração do segundo aniversário do Ano X da Revolução Nacional (Braga, 1946). Integrou, entre outros elementos, cerimónias com discursos, missa campal e paradas (França 2012, 123-143), emulando a estratégia propagandística da década anterior (Matos 2010), que coincidiu com uma estetização da política, por via de celebrações periódicas e rituais coreografados, presentes noutros regimes autocráticos (e.g. Mosse 1975; Gentile 1996, 80-101). O recurso à espetacularização como envolvimento constituiu um instrumento para concretizar o desígnio de moldar a sociedade portuguesa aos valores salazaristas, aspecto significativo para perpetuar o regime (Rosas 2013, 341-348).

4 Nesta conjuntura, a exposição Quinze Anos de Obras Públicas (1932-1947) de 1948 procurou sustentar a preservação do Estado Novo, que então perpetuou e atualizou práticas propagandísticas comemorativas de autoengrandecimento (Ferreira 2019, 30). Conforme à conceção teleológica adscrita à ação política do regime (Cunha 1994, 79-80), a divulgação da obra feita demonstraria capacidades de concretização e inovação, justificando a prossecução do desenvolvimento infraestrutural na metrópole. A política de obras públicas foi um dos elementos fulcrais da política económica do Estado Novo (Nunes e Brito 1992, 317). Encerrava aspirações simbólicas, corporizando a autoridade estatal no território, e representava os propósitos da atuação do regime em contraste com a desordem da I República (Ferreira 2019, 24-25). Materializou a modernidade do regime, sendo a arquitetura oficial encarada como rosto do idealizado "renascimento nacional" e representação simbólica do poder político (Brites 2017). Num momento de crise, a apresentação pública das realizações e dos planos para o futuro próximo, compassados com a prevista linha de fomento industrial e a aposta em melhoramentos rurais, era estratégica.

5 Considera-se que o regime organizou, no pós-guerra, exposições políticas definidas como locais de construção de identidade nacional, nos quais era possível criar, disseminar e venerar mitos sobre as origens da nação, e forjar genealogias conectando o presente ao passado recente ou remoto (Schnapp 2007, 78). Também Mussolini, Hitler e Franco promoveram estas exposições como elemento inclusivo e antielitista de mobilização coletiva para obtenção do suporte das massas (e.g. Mosse 1975; Gentile 1996; Stone 1998; Schnapp 2007; Basilio 2013; Tymkiw 2018).

6 Embora menos individualizada do que outras exposições antecedentes (e.g. Acciaiuoli 1998; Corkil e Almeida 2009; Serra e Parreira 2017; Gori 2018a, 2018b), a exposição Quinze Anos de Obras Públicas (1932-1947) foi já considerada pela historiografia. Face à necessidade de «um balanço que pudesse funcionar como tampão às mudanças» do pósguerra (Acciaiuoli 1991, 473) e de assegurar apoio ao Governo, vincou-se a iniciativa como glorificação da ação do Ministro Duarte Pacheco (1900-1943), e como exaltação do regime enquanto redentor do país (Lira 2002, 215). Salientou-se a ligação ao I Congresso Nacional de Arquitetura (França 1991, 438-439), marco que permitiu que jovens arquitetos manifestassem, a par de reivindicações sociais do foro da habitação e do urbanismo, o seu antagonismo às imposições estéticas oficiais ${ }^{1}$ (Portas 2008, 198-199). A exposição funcionou «como elemento de acusação» (França 1991, 440), alavancando a afirmação dos engenheiros enquanto classe (Ribeiro 2008). O seu papel político foi 
analisado através dos discursos e do aparato cerimonial nas sessões solenes (Abreu 2006, 105-172), e dos textos do guia e do documentário cinematográfico que a acompanharam (Ferreira 2019, 30-35).

7 Neste artigo aborda-se a exposição Quinze Anos de Obras Públicas (1932-1947) considerando o emprego de mecanismos de propaganda expositiva anteriores como forma de legitimação e preservação do regime, através de aspetos ainda pouco focados na historiografia. Equaciona-se, de antemão, a afinidade conceptual com exposições estrangeiras. Analisa-se a comissão organizadora e a equipa de decoradores, numa abordagem que beneficia de estudos sobre o aparelho burocrático que definiu a encomenda de edifícios públicos, e sobre as relações entre arquitetos e organismos oficiais (Ribeiro 1993; Brites 2015, 2017; Carvalho 2018). Nesta sequência, atenta-se na linguagem expositiva numa perspetiva abrangente, em comparação com exposições oficiais anteriores. Não se descura a influência exercida por exposições estrangeiras na década de 1930, particularmente as fascistas (Serra e Parreira 2017; Lobo e Alves 2017; Gori 2018a), que haviam adaptado às suas intenções propagandísticas as preocupações de «receção coletiva simultânea» (Benjamin 2012, 83-84) e o experimentalismo imersivo e sensorial desenvolvidos por El Lissiztky e por antigos membros da Bauhaus, como Gropius e Bayer (Pohlmann 1999; Klonk 2009, 108-113).

8 Metodologicamente, este artigo parte da análise de fontes decorrentes da exposição em análise, como fotografias, publicações e discursos, documentação arquivística $^{2}$ e bibliografia.

\section{A ideia para «uma grande exposição documentária»: contextos}

9 A ideia de «uma grande exposição documentária» (Ulrich 1948a, 17) partiu de José Frederico Ulrich (1905-1982), o primeiro ministro das Obras Públicas nomeado após a cisão com a pasta das Comunicações. Em 1947, Ulrich realizara uma viagem pelo país para conhecer os melhoramentos públicos realizados, numa estratégia de planificação dos investimentos vindouros (Ferreira 2019, 29). Considerou-se que a vasta obra iniciada há 15 anos deveria ser «amplamente conhecida»³. Salazar, discursando em 1945 no contexto da dissolução da Assembleia Nacional, já se referira ao desconhecimento, particularmente na capital, das realizações empreendidas no país (Salazar 1951, 186-187). Considera-se que este discurso e a exposição pretendiam desacreditar os detratores do regime, e conquistar a confiança da população.

10 Como sustentáculo, a exposição incorporou uma homenagem simultânea ao impulsionador das obras públicas, Duarte Pacheco. Não se buscava legitimação através de heróis do passado distante, apostando-se na mitificação de uma figura do presente, que representava a modernização do país levada a cabo pelo regime. A realização no IST, onde Duarte Pacheco, Ulrich e muitos dos engenheiros participantes se formaram, detinha múltiplo simbolismo, considerando que as instalações, concretizadas sob Pacheco, se converteram no ex-líbris da modernidade do regime, num dos eixos urbanos da capital reabilitados por intervenção estatal.

11 O investimento nas obras públicas portuguesas fora já sinteticamente apresentado nos certames internacionais de Paris (1937), Nova Iorque e S. Francisco (1939) (Santos 1994; Acciaiuoli 1998; Neto 2016). Porém, a evidência do poder da arquitetura e do fomento 
oficial de obras públicas ficara particularmente patente, a nível interno, na exposição itinerante Moderna Arquitetura Alemã (Lisboa, 1941). Integrou fotografias e maquetas de grande dimensão de edificações do III Reich, e foi visitada por arquitetos que laboraram para encomendas oficiais do Estado Novo, como Cristino da Silva (1896-1976) e Cottinelli Telmo (1897-1948), arquiteto-chefe da Exposição do Mundo Português (Zech 2005, 43). O último, considerando-a como lição abrangente, dado que os edifícios alemães foram realizados para «a compreensão das massas» (Telmo 1941, 5), equaciona a realização de uma exibição idêntica para o caso português:

[...] nós portugueses, que vivemos uma época construtiva em todo o sentido, sentimos ao visitar esta exposição quanto o governo português tem feito para dotar a nação com as obras que hão-de assegurar o funcionamento perfeito e com dignidade da máquina nacional. 0 que seria uma exposição de maquetes de tudo o que se tem feito em Portugal nos últimos anos em matéria de arquitetura, urbanismo e obras de arte? Alguém pensou já na grandeza de semelhante exposição, sobretudo se nos não limitássemos a maquetes de coisas feitas, mas de tudo o que está projetado? (Telmo 1941, 5)

12 Já em 1939, Pardal Monteiro (1897-1957) apresentara ao Sindicato Nacional dos Arquitetos (SNA) a sugestão de realizar uma exposição e um congresso de arquitetura nacionais, para coincidir com as comemorações centenárias, sem seguimento (Ribeiro 1993, 267-268, 329-331).

13 Em termos propagandísticos, a exposição Quinze Anos de Obras Públicas (1932-1947), de 1948, parece possuir afinidades com a alemã, que pretendera mostrar as realizações do regime e divulgá-las como conquistas da Nação (Zech 2005, 19). Apesar da centralidade de maquetas e de fotografias em ambas, diferiram no domínio estético, revelando-se a alemã mais convencional, sem presença de dados estatísticos. Tratava-se de uma exposição de propaganda externa, com um tom positivo para não hostilizar os anfitriões (Zech 2005, 7).

Também em Espanha se realizaram exposições com intentos semelhantes, conceptualmente afins à exposição de 1948. Num espírito de confirmação do regime franquista, a Dirección General de Regiones Devastadas organizou, desde 1940, exposições itinerantes pelo país, demonstrando a capacidade criadora da obra de reconstrução nacional com projetos realizados e planeados (Ortuño 2016, 70-77). Em 1942, coincidindo com a passagem da exposição alemã por Madrid, a Dirección General de Arquitectura organizou uma mostra dos seus mais simbólicos projetos urbanísticos, habitacionais e de edifícios públicos (Dirección 1942; Mosteiro 2003, 258). Não se comprovou a visita destas exposições por parte de portugueses, embora fossem, pelo menos, do conhecimento do embaixador de Portugal em Madrid ${ }^{4}$, Pedro Teotónio Pereira (1902-1972), estreito colaborador de Salazar. Refira-se que os arquitetos ibéricos mantiveram contactos neste período. 0 convite espanhol para organizar uma reunião luso-espanhola originou debate no SNA, vindo a realizar-se paralelamente ao III Congresso da Federación de Urbanismo y de la Vivienda, em 1944. Salazar manifestou interesse em realizar e subsidiar uma exposição nacional de arquitetura para essa ocasião, sem efetivação. A exposição foi novamente endereçada aquando da planificação da segunda reunião, sem gerar consenso no SNA. O IV Congresso da federação espanhola foi adiado para 1947, iniciado em Lisboa e coincidindo com as comemorações da Tomada de Lisboa aos Mouros. Incluiu uma pequena mostra de projetos urbanísticos do Ministério das Obras Públicas (Ribeiro 1993, 313-327, 408). 

nova formulação ministerial separou as pastas das obras públicas e das comunicações ${ }^{5}$, e o início de um ciclo de investimentos em melhoramentos rurais ${ }^{6}$ tornou necessário envolver organismos regionais e população para continuar a modernização infraestrutural do país. Numa conjuntura política instabilizada por movimentos oposicionistas, e face à organização de grupos de jovens arquitetos questionando as práticas oficiais, chegara a altura de concretizar uma exposição política oficial, afastada dos condicionalismos internos do SNA.

Se a exposição Quinze Anos de Obras Públicas (1932-1947) de 1948, inaugurada na data simbólica do 22.. aniversário da revolução de 1926, integrou uma tática de propaganda interna com público-alvo eminentemente nacional ${ }^{7}$ - com um total assinalável de 500.000 visitantes nos cinco meses de abertura (Moura 1948) -, constituiu, paralelamente, uma manifestação do progresso e das preocupações sociais do regime para o exterior, num momento de solicitação do auxílio do Plano Marshall (Rollo 2007). Foi visitada, por exemplo, por grupos de arquitetos e ferroviários franceses. Porventura constituiu, também, uma jogada nas relações ibéricas que se vinham reforçando desde 1942 (Rezola 2008): a impossibilidade de Franco vir a Portugal em 1948, ano de renovação do pacto de não-agressão (Fernández 2000, 131-132), não impediu que os seus Ministros das Obras Públicas e da Educação visitassem a exposição (Anónimo 1948a, 200).

\section{Organizadores e decoradores}

17 A organização da exposição esteve a cargo de uma comissão executiva, que laborou sob orientação do Ministro das Obras Públicas, José Frederico Ulrich, sendo presidida pelo engenheiro Eduardo Rodrigues de Carvalho (1891-1970) e composta pelos vogais: o arquiteto Jorge Segurado (1898-1990), Mário Costa Ferreira Lima (1889-?), representante do Ministério das Finanças ${ }^{8}$, e o secretário engenheiro Mário de Sandy Lopes Pessoa Jorge (1922-1990). Ter-se-á tratado de uma escolha tática para efetivar as pretensões de legitimação oficial.

Rodrigues de Carvalho e Segurado terão preponderado, atentando no destaque que Ulrich lhes conferiu em discurso, que levaria à condecoração com graus da Ordem de Cristo (Santos 2009, 125-126), bem como na intervenção de ambos na apresentação da exposição inserida nas publicações complementares. Lima e Pessoa Jorge não intervieram publicamente, mas seriam também condecorados no encerramento da exposição (Anónimo 1948b, 243).

Rodrigues de Carvalho', major de engenharia, foi um dos homens de confiança de Duarte Pacheco, tendo sido chefe de gabinete do Ministro. Integrou a Direção Geral dos Edifícios e Monumentos Nacionais (DGEMN) em 1934, vindo a chefiar a Repartição de Estudos e Edifícios e a incorporar a Comissão de Revisão. Colaborou, entre várias outras, nas obras das Gares Marítimas e do Estádio Nacional, supervisionando um amplo leque de projetos. Dirigiu os Serviços de Urbanização e Obras da Câmara Municipal de Lisboa (1938-1944), acumulando a substituição da presidência do município - até então ocupada por Duarte Pacheco, de regresso às Obras Públicas. Paralelamente, foi Engenheiro Inspetor do Conselho Superior de Obras Públicas, e, ainda, vogal da Comissão Nacional dos Centenários e membro do conselho de administração da Companhia Portuguesa de Celulose. A sua presença asseguraria a 
componente de homenagem a Pacheco, e a sua experiência prática e transversal no setor tornavam-no imprescindível para a narrativa pretendida para a exposição. Simultaneamente, esta seleção permitia silenciar e ocupá-lo: o engenheiro não fora convidado para a cerimónia de inauguração do Estádio Nacional em 1944, o que o levou a sublinhar, em ofício a Salazar, a coautoria de Pacheco nessa obra (Costa 2012, 27).

Jorge Segurado também colaborara com obras oficiais. Foi arquiteto da DGEMN e chefe da sua Repartição de Estudos de Urbanização, projetando diversos edifícios públicos inovadores, como a Casa da Moeda. Participava em exposições oficiais há mais de uma década, tendo sido o primeiro arquiteto-chefe dos serviços técnicos do Secretariado de Propaganda Nacional - SPN (Galvão 2003, 338-339; Santos 2009, 291). Planificou recintos expositivos na capital ${ }^{10}$ e integrou a equipa que, sob António Ferro (1895-1956) - de quem foi um dileto colaborador (Santos 2009, 269-270) -, concretizou pavilhões para exposições internacionais ${ }^{11}$, supervisionando a decoração das salas. Colaborou no núcleo das aldeias portuguesas da Exposição do Mundo Português, e assinou o projeto de adaptação do Museu de Arte Popular. Demonstrou capacidade de coordenar equipas e promover a encenação da modernidade do regime em exposições, ao que acrescia a sua experiência em edifícios públicos, podendo ser considerada, portanto, uma escolha conveniente.

21 A exposição encerrava duas partes distintas: o pavilhão central com salas dedicadas ao elogio do regime e à síntese da atividade Ministério, e três núcleos temáticos sobre as várias dimensões das obras públicas e comunicações. A primeira contou com uma secção retrospetiva, coordenada por Manuel Santos Estevens (1913-2001), bibliotecárioarquivista do Ministério das Finanças ${ }^{12}$, que se empenhara na preservação de património arquivístico e artístico, visitando bibliotecas e arquivos pelo país ("Curriculum Vitae", 1946), uma experiência útil na tarefa de seleção de documentos históricos que lhe competiu na exposição.

A outra parte da exposição dividia-se por secções correspondentes a serviços do Ministério (tabela n. ${ }^{2}$ ), integrando, adicionalmente, secções dedicadas ao turismo, ao Comissariado de Desemprego e à Câmara Municipal de Lisboa.

Tabela 1 - Exposição Quinze Anos de Obras Públicas: Secções, Núcleos e Intervenientes

Fonte: "Comissão Executiva da Exposição de Obras Públicas" (1948)

\begin{tabular}{|l|l|l|l|}
\hline Secção & Núcleo & Delegado(s) & Decorador(es) \\
\hline Comunicações & $\begin{array}{l}\text { Administração Geral dos } \\
\text { Correios, Telégrafos e e } \\
\text { Telefones }\end{array}$ & $\begin{array}{l}\text { Eng. José Maria } \\
\text { Camolino Ferraz de } \\
\text { Matos e Silva }\end{array}$ & $\begin{array}{l}\text { Abílio de Matos e Silva } \\
\text { (desenhador, decorador), } \\
\text { Carlos Ribeiro (pintor, } \\
\text { decorador) }\end{array}$ \\
\hline Comunicações & Junta Autónoma de Estradas & $\begin{array}{l}\text { Silva Carvalho, Arq. } \\
\text { Inácio Perez } \\
\text { Fernandes }\end{array}$ & $\begin{array}{l}\text { Carlos Botelho (pintor, } \\
\text { decorador) }\end{array}$ \\
\hline Comunicações & $\begin{array}{l}\text { Direção Geral dos Serviços de } \\
\text { Viação }\end{array}$ & $\begin{array}{l}\text { Eng. Mário José de } \\
\text { Abreu e Silva }\end{array}$ & $\begin{array}{l}\text { Carlos Botelho (pintor, } \\
\text { decorador) }\end{array}$ \\
\hline
\end{tabular}




\begin{tabular}{|c|c|c|c|}
\hline Comunicações & $\begin{array}{l}\text { Direção Geral dos Caminhos } \\
\text { de Ferro }\end{array}$ & $\begin{array}{l}\text { Eng. António Alfredo } \\
\text { Sanches de Castro da } \\
\text { Costa Macedo }\end{array}$ & $\begin{array}{lr}\text { Manuel } & \text { Correia } \\
\text { (decorador), } & \text { Baptista } \\
\text { Gouveia (decorador) }\end{array}$ \\
\hline Comunicações & $\begin{array}{l}\text { Direção Geral da Aeronáutica } \\
\text { Civil }\end{array}$ & $\begin{array}{l}\text { Eng. José Manuel } \\
\text { Gonçalves Figueira }\end{array}$ & José Espinho (decorador) \\
\hline Comunicações & As Obras Públicas no Turismo & $\begin{array}{l}\text { Dr. A. Tavares de } \\
\text { Almeida }\end{array}$ & $\begin{array}{l}\text { Frederico George (pintor, } \\
\text { decorador, } \\
\text { Eduardo } \\
\text { (decorador) }\end{array}$ \\
\hline Hidráulica & $\begin{array}{l}\text { Junta Autónoma das Obras de } \\
\text { Hidráulica Agrícola }\end{array}$ & $\begin{array}{l}\text { Eng. Viriato de } \\
\text { Noronha de Castro } \\
\text { Cabrita }\end{array}$ & $\begin{array}{l}\text { Fred Kradolfer (pintor, } \\
\text { decorador) }\end{array}$ \\
\hline Hidráulica & $\begin{array}{l}\text { Administração Geral do Porto } \\
\text { de } \quad \text { Lisboa } \quad \text { (inclui } \\
\text { Administração dos } \\
\text { Dortos do } \\
\text { Douro e }\end{array}$ & $\begin{array}{l}\text { Eng. Fernando César } \\
\text { dos Santos Silva, Arq. } \\
\text { Paulo Henrique de } \\
\text { Carvalho e Cunha; } \\
\text { *Eng. Henrique } \\
\text { Schreck }\end{array}$ & $\begin{array}{l}\text { Paulo Henrique de } \\
\text { Carvalho e Cunha } \\
\text { (arquiteto), colaboração } \\
\text { de Fred Kradolfer (pintor, } \\
\text { decorador); } \\
\text { Araújo Robrto de } \\
\text { decorador) }\end{array}$ \\
\hline Hidráulica & $\begin{array}{l}\text { Direção Geral dos Serviços } \\
\text { Hidráulicos }\end{array}$ & $\begin{array}{l}\text { Eng. Francisco Vaz } \\
\text { Pacheco de Castro, } \\
\text { Eng. Sebastião Mário } \\
\text { da Silveira Durão, } \\
\text { Arq. Inácio Perez } \\
\text { Fernandes }\end{array}$ & $\begin{array}{l}\text { Roberto de Araújo } \\
\text { (pintor, decorador) }\end{array}$ \\
\hline Hidráulica & $\begin{array}{l}\text { Comissão de Obras da Base } \\
\text { Naval de Lisboa }\end{array}$ & $\begin{array}{l}\text { Eng. Francisco } \\
\text { Augusto Rosa }\end{array}$ & $\begin{array}{l}\text { Carlos Rebelo de Andrade } \\
\text { (arquiteto), Jorge } \\
\text { Barradas (pintor) }\end{array}$ \\
\hline Hidráulica & $\begin{array}{l}\text { Aproveitamentos } \\
\text { hidroagrícolas }\end{array}$ & $\begin{array}{l}\text { Eng. Viriato de } \\
\text { Noronha de Castro } \\
\text { Cabrita }\end{array}$ & $\begin{array}{ll}\text { Ticiano } & \text { Violante } \\
\text { (maquetista) } & \end{array}$ \\
\hline Hidráulica & $\begin{array}{l}\text { Aproveitamentos } \\
\text { hidroelétricos }\end{array}$ & $\begin{array}{lrr}\text { Eng. José } & \text { Filipe } \\
\text { Rebelo Pinto, } & \text { Eng. } \\
\text { Francisco } & \text { Vaz } \\
\text { Pacheco de } & \text { Castro, } \\
\text { Arq. Inácio } & \text { Perez } \\
\text { Fernandes } & \end{array}$ & $\begin{array}{l}\text { Roberto de Araújo } \\
\text { (pintor, decorador) }\end{array}$ \\
\hline Urbanização & $\begin{array}{l}\text { Comissão de Fiscalização de } \\
\text { Levantamentos Topográficos } \\
\text { Urbanos }\end{array}$ & $\begin{array}{l}\text { Eng. Paulo Quaresma } \\
\text { Ventura }\end{array}$ & $\begin{array}{l}\text { Frederico George (pintor, } \\
\text { decorador, arquiteto) }\end{array}$ \\
\hline
\end{tabular}




\begin{tabular}{|c|c|c|c|}
\hline Urbanização & $\begin{array}{l}\text { Direção Geral dos Serviços de } \\
\text { Urbanização }\end{array}$ & $\begin{array}{l}\text { Eng. Alberto Saraiva e } \\
\text { Sousa; Arq. António } \\
\text { Gomez Egea }\end{array}$ & $\begin{array}{l}\text { Frederico George (pintor, } \\
\text { decorador, arquiteto) }\end{array}$ \\
\hline Urbanização & $\begin{array}{l}\text { Gabinete de Urbanização da } \\
\text { Costa do Sol }\end{array}$ & $\begin{array}{l}\text { Eng. João Paulo } \\
\text { Nazaré d'Oliveira }\end{array}$ & José Espinho (decorador) \\
\hline Urbanização & $\begin{array}{l}\text { Comissão Administrativa das } \\
\text { Obras do Estádio Nacional }\end{array}$ & $\begin{array}{l}\text { Eng. Júlio José Netto } \\
\text { Marques }\end{array}$ & $\begin{array}{l}\text { Frederico George (pintor, } \\
\text { decorador, arquiteto) }\end{array}$ \\
\hline Urbanização & Águas de Lisboa & $\begin{array}{l}\text { Eng. António Gentil } \\
\text { Soares Branco }\end{array}$ & $\begin{array}{l}\text { Luís Gentil Soares Branco } \\
\text { (arquiteto) }\end{array}$ \\
\hline Urbanização & Comissariado do Desemprego & $\begin{array}{l}\text { Eng. Eduardo Ferreira } \\
\text { da Silva }\end{array}$ & $\begin{array}{l}\text { Carlos Botelho (pintor, } \\
\text { decorador) }\end{array}$ \\
\hline Urbanização & Câmara Municipal de Lisboa & $\begin{array}{l}\text { Eng. Mário Maurício } \\
\text { Miguel dos Santos }\end{array}$ & José Espinho (decorador) \\
\hline Urbanização & $\begin{array}{l}\text { O problema da habitação } \\
\text { (Direção Geral dos Serviços de } \\
\text { Urbanização, Direção Geral } \\
\text { dos Edifícios e Monumentos } \\
\text { Nacionais, Câmara Municipal } \\
\text { de Lisboa) }\end{array}$ & $\begin{array}{l}\text { Eng. Alberto Saraiva e } \\
\text { Sousa }\end{array}$ & $\begin{array}{l}\text { Frederico George (pintor, } \\
\text { decorador, arquiteto) }\end{array}$ \\
\hline $\begin{array}{l}\text { Urbanização } \\
\text { Edifícios } \\
\text { Monumentos }\end{array}$ & $\begin{array}{l}\text { Direção Geral dos Edifícios e } \\
\text { Monumentos } \\
\text { (Monumentos) }\end{array}$ & $\begin{array}{l}\text { Arq. Baltazar de } \\
\text { Castro }\end{array}$ & $\begin{array}{l}\text { Roberto de Araújo } \\
\text { (pintor, decorador) }\end{array}$ \\
\hline $\begin{array}{l}\text { Urbanização } \\
\text { Edifícios } \\
\text { Monumentos }\end{array}$ & $\begin{array}{l}\text { Comissão Administrativa das } \\
\text { Novas Instalações para o } \\
\text { Exército }\end{array}$ & $\begin{array}{l}\text { Eng. Filipe Francisco } \\
\text { Pereira }\end{array}$ & $\begin{array}{l}\text { Fred Kradolfer (pintor, } \\
\text { decorador) }\end{array}$ \\
\hline $\begin{array}{l}\text { Urbanização } \\
\text { Edifícios } \\
\text { Monumentos }\end{array}$ & 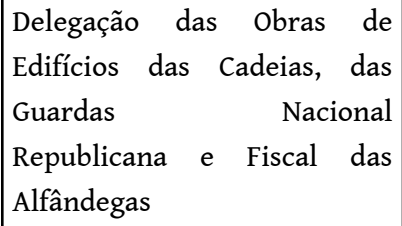 & $\begin{array}{l}\text { Eng. Heitor de } \\
\text { Mascarenhas Inglês }\end{array}$ & $\begin{array}{lll}\text { Jorge Santos } & \text { Costa } \\
\text { (arquiteto), Vasco } & \text { Costa } \\
\text { (decorador) } & \end{array}$ \\
\hline $\begin{array}{l}\text { Urbanização } \\
\text { Edifícios } \\
\text { Monumentos }\end{array}$ & $\begin{array}{l}\text { Direção Geral dos Edifícios e } \\
\text { Monumentos } \\
\text { (Edifícios) }\end{array}$ & 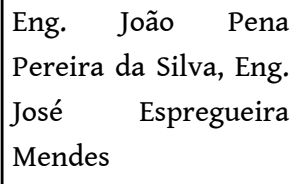 & $\begin{array}{l}\text { Roberto de Araújo } \\
\text { (pintor, decorador) }\end{array}$ \\
\hline $\begin{array}{l}\text { Urbanização } \\
\text { Edifícios } \\
\text { Monumentos }\end{array}$ & $\begin{array}{l}\text { Comissão Administrativa dos } \\
\text { Novos Edifícios Universitários }\end{array}$ & $\begin{array}{lr}\text { Eng. } & \text { Eduardo } \\
\text { Evangelista } & \text { de } \\
\text { Carvalhal } & \end{array}$ & $\begin{array}{l}\text { Roberto de Araújo } \\
\text { (pintor, decorador) }\end{array}$ \\
\hline $\begin{array}{l}\text { Urbanização } \\
\text { Edifícios } \\
\text { Monumentos }\end{array}$ & $\begin{array}{l}\text { Comissão de Obras da } \\
\text { Leprosaria } \\
\text { Pais }\end{array}$ & $\begin{array}{l}\text { Eng. João Ribeiro } \\
\text { Fráguas }\end{array}$ & $\begin{array}{l}\text { Roberto de Araújo } \\
\text { (pintor, decorador) }\end{array}$ \\
\hline
\end{tabular}




\begin{tabular}{|c|c|c|c|c|}
\hline $\begin{array}{l}\text { Urbanização } \\
\text { Edifícios } \\
\text { Monumentos }\end{array}$ & e & $\begin{array}{l}\text { Comissão das Construções } \\
\text { Hospitalares }\end{array}$ & $\begin{array}{l}\text { Eng. Jaime Rodrigues } \\
\text { Nina }\end{array}$ & $\begin{array}{l}\text { Roberto de Araújo } \\
\text { (pintor, decorador) }\end{array}$ \\
\hline $\begin{array}{l}\text { Urbanização } \\
\text { Edifícios } \\
\text { Monumentos }\end{array}$ & e & $\begin{array}{l}\text { Comissão Administrativa das } \\
\text { Obras da Cidade Universitária } \\
\text { de Coimbra }\end{array}$ & Arq. Cottinelli Telmo & $\begin{array}{l}\text { Cottinelli } \\
\text { (arquiteto) }\end{array}$ \\
\hline $\begin{array}{l}\text { Urbanização } \\
\text { Edifícios } \\
\text { Monumentos }\end{array}$ & e & $\begin{array}{l}\text { Junta das Construções para o } \\
\text { Ensino Técnico e Secundário }\end{array}$ & Arq. José Costa e Silva & $\begin{array}{l}\text { Roberto de Araújo } \\
\text { (pintor, decorador) }\end{array}$ \\
\hline $\begin{array}{l}\text { Urbanização } \\
\text { Edifícios } \\
\text { Monumentos }\end{array}$ & e & $\begin{array}{l}\text { Delegação para as Obras de } \\
\text { Construção de Escolas } \\
\text { Primárias }\end{array}$ & $\begin{array}{l}\text { Eng. Pedro Sebastião } \\
\text { de Morais Sarmento } \\
\text { Campilho }\end{array}$ & $\begin{array}{l}\text { Roberto de Araújo } \\
\text { (pintor, decorador) }\end{array}$ \\
\hline
\end{tabular}

Sob orientação geral de Segurado, que reclamaria a total orientação criativa da exposição (Santos 2009, 141), e para evitar monotonia através da repetição de elementos, acometeu-se a organização de cada secção ao serviço representado, aconselhando-se recorrer a um artista decorador com experiência comprovada para orientar a disposição espacial (Carvalho 1948b, 21). Quanto aos delegados das secções, é expressiva a preponderância de 26 engenheiros sobre seis arquitetos, evidenciando o seu predomínio nas pastas de obras públicas e comunicações (cf. tabela n.ำ1).

24 A maioria dos decoradores, com formação e obra no campo das artes gráficas, possuía experiência em exposições, tendo integrado a equipa do SPN e trabalhado com Jorge Segurado nos certames internacionais, como nos casos de Carlos Botelho (1899-1982), Fred Kradolfer (1903-1968), Roberto de Araújo (1909-1969) e Eduardo Anahory $(1917-1985)^{13}$. A presença de alguns arquitetos como decoradores fundamenta-se pela sua atividade nas comissões de obras, como Carlos Rebelo de Andrade (1887-1971) na Base Naval de Lisboa. Do grupo de decoradores que mais salas planeou, destaque-se Frederico George (1915-1994) e José Espinho (1915-1973). Particularmente George ${ }^{14}$ viria a ter um papel marcante na autonomização e afirmação progressiva do design expositivo no país. A função de decoração plástica do espaço estipulado pelo arquitetochefe, dominante até então, dará lugar nas décadas seguintes ao ato integral de projetar exposições, com criação total do ambiente através do desenho específico de elementos de museografia e mobiliário (Manaças 2005). Espinho destacou-se na decoração de interiores e na conceção de mobiliário, colaborando em exposições do município de Lisboa. Seria também um nome de referência na institucionalização do design como disciplina ${ }^{15}$.

Jorge Segurado exprimiu o critério que presidiu à organização, referindo-se à liberdade de composição dada a cada decorador na sua secção, após definição da distribuição geral da exposição, para que esta fosse equilibrada e dominasse uma certa unidade estética no conjunto ${ }^{16}$, elogiando os colaboradores escolhidos: «o visitante não pode ficar indiferente às manifestações de gosto, de cuidado e de competência profissional de cada decorador, na criação da moldura da parte que lhe correspondeu» (Segurado 1948, 182). 
Recorreu-se a um grupo de artistas e arquitetos que constituíam a vanguarda que se «predispusera [...] à normalização» (ó 1999, 115) na década anterior, familiarizada com a participação em exposiç̃os políticas e obras públicas. Não foram selecionados artistas comprovadamente avessos ao regime ou à estética oficialmente privilegiada. No pósguerra, mediante as manifestações políticas de determinados artistas, não terá havido aposta oficial nas novas gerações (ó 1999, 222-225), apesar da lógica oficial inclusiva de integração e compromisso (Brites 2015, 2017). Frederico George, por exemplo, seria exonerado da docência por seis anos em 1949 por motivos políticos, mas participaria em importantes exposições oficiais nos anos de 1950 (Souto 1993). Acresce que os decoradores colaboravam com delegados empenhados em apresentar exemplarmente as obras públicas em que intervinham profissionalmente. A participação seria um fator de prestígio na carreira destes engenheiros. A diferença fundamental face a exposições anteriores reside no facto de a decoração artística, através de pinturas murais e esculturas alegóricas, ter sido pontual e circunscrita. 0 trabalho dos decoradores incidiu sobretudo no design expositivo, concebendo elementos gráficos ${ }^{17} \mathrm{e}$ suportes para conteúdos e objetos.

\section{A linguagem expositiva: encenação e clareza}

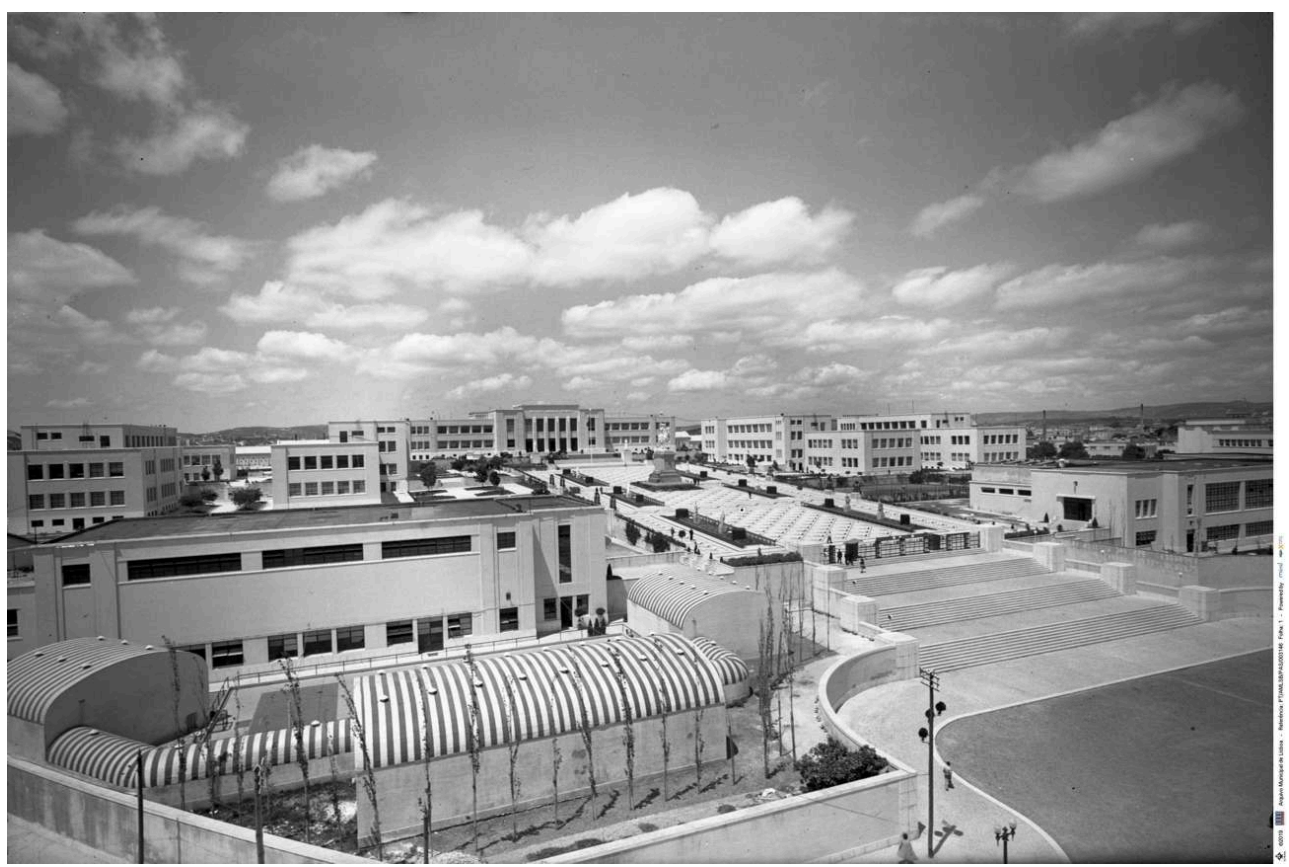

Fig. 1 - Perspetiva geral do recinto da exposição Quinze Anos de Obras Públicas no Instituto Superior Técnico, Lisboa. No canto inferior esquerdo, observam-se os pavilhões provisórios do núcleo 'O problema da habitação', e na alameda central os modelos de estátuas, 1948.

Fotografia de António Passaporte @ A Arquivo Municipal de Lisboa, PT/AMLSB/PAS/003146

A exposição, que ocupou cerca de $7000 \mathrm{~m}^{2}$ no IST, assumiu um tom de divulgação acessível ao grande público não especializado, de apreensão imediata e, sobretudo, visual, sem «charadas por resolver» (Moura 1948, s/p). Não se circunscrevia a detalhes que pudessem interessar apenas a uma diminuta elite erudita, nem apresentava «demasiadas preocupações de rigor técnico» (Carvalho 1948a, 20), enaltecendo-se as 
vantagens do progresso como resolução dos problemas nacionais e fator de melhoria das condições de vida.

Rodrigues de Carvalho esclareceu a orientação dos conteúdos, prevendo que as reações dos visitantes incidiriam «em especial sobre o que se lhes apresenta e o modo como lhes é apresentado» (Carvalho 1948b, 20). A compreensão do ato de encenação patente no discurso expositivo era inequívoca, justificando a manipulação e ocultação de factos de modo a favorecer o regime. Importava demonstrar a ação oficial de modo claro e inquestionável, apostando-se na apresentação de dados estatísticos, equipamento técnico e edificações, reforçados através de citações estrategicamente escolhidas, sobretudo de Salazar e Pacheco.

Para além das possíveis influências conceptuais pelas supracitadas exposições alemã e espanholas, a hipótese que sugerimos é que em termos de discurso expositivo, Jorge Segurado terá conjugado o que observou na Deutsche Bauausstellung (Berlim, 1931) ${ }^{18}$ (Galvão 2003, 249) com a experiência adquirida com o SPN nas mostras internacionais.

A entrada no pavilhão central do IST fazia-se pelo átrio de honra, no qual figuravam as estátuas de Salazar e de Óscar Carmona, colocadas vis-à-vis, já presentes nas exposições de Paris e de Nova Iorque. Neste tipo de exposições, o átrio constituía um espaço de receção para preparação do visitante para a entrada no ambiente expositivo ${ }^{19}$.

31 Seguia-se a sala com a maqueta da Exposição do Mundo Português, enaltecendo Salazar enquanto possibilitador desse magno evento, e o projeto do monumento de homenagem a Duarte Pacheco, delineado por Cottinelli Telmo e Leopoldo de Almeida (1898-1975) como um altar com alegorias à Visão, ao Entusiasmo e à Tenacidade na base (Anónimo 1948c, 41), que não fora ainda concretizado. Rodrigues de Carvalho lançara a proposta para o monumento em 1943 e a sua edificação arrastou-se por dez anos (Costa 2012, 22, 29-36), diferindo a maqueta da configuração final do monumento inaugurado em Loulé, projetado por Cristino da Silva (Abreu 2006, 395-430).

Na parede fundeira da sala fixaram-se palavras do Presidente do Conselho, num elogio do progresso alcançado sob sua coordenação: «São coisas muito grandes a passarem do sonho para a realidade da vida ante os nossos olhos atónitos de tanto nos haver a decadência habituado a tê-las por impossíveis». Apresentavam-se, também, mapas e tabelas concernindo o resumo financeiro da atividade do Ministério das Obras Públicas e Comunicações (fig. 2). 


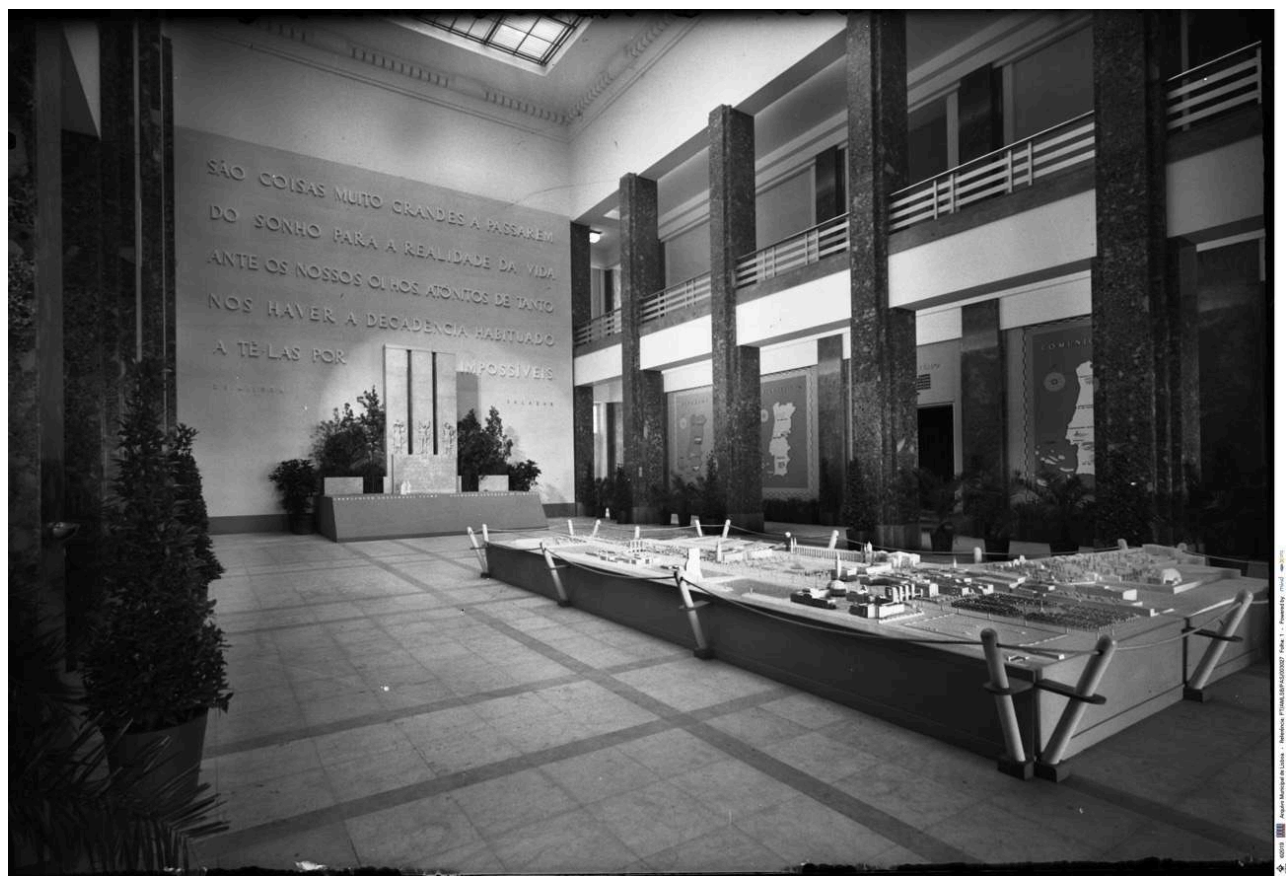

Fig. 2 - Exposição Quinze Anos de Obras Públicas, Sala da Síntese Financeira: maquetas da Exposição do Mundo Português e do Monumento a Duarte Pacheco, 1948.

Fotografia de António Passaporte @ Arquivo Municipal de Lisboa, PT/AMLSB/PAS/003027

A sala retrospetiva compreendia documentação e bibliografia provenientes de bibliotecas e arquivos públicos ("Comissão Executiva da Exposição de Obras Públicas", 1948). Do Livro das Fortalezas de Duarte de Armas (séc. XVI) a plantas de igrejas, estudos de urbanização, ilustrações de obras de engenharia e arquitetura, e levantamentos topográficos e hidrográficos, os exemplares expostos incidiram predominantemente sobre Setecentos, com destaque para a reconstrução pombalina de Lisboa. Também constava o decreto de criação do Ministério das Obras Públicas, Comércio e Indústria, nomeando Fontes Pereira de Melo (1852), e aludindo à linhagem que precedia os empreendimentos sob Duarte Pacheco. No final do percurso era possível visionar o documentário propositadamente realizado por António Lopes Ribeiro ${ }^{20}$, sendo a exibição de filmes propagandísticos já uma prática comum, sobretudo nos certames internacionais (Neto 2016, 20; Santos 2009, 308).

O cerne da exibição consistia nas secções temáticas de Comunicações, Hidráulica e Urbanização (subdividida nas secções 'Edifícios' e 'Urbanização', e incluindo 'O problema da habitação'). Para as secções de Comunicações e de Hidráulica, Segurado projetou dois pavilhões provisórios idênticos, por se ter verificado a insuficiência da área disponível para a totalidade dos serviços a apresentar (fig. 3). Para a secção de Urbanização, foram adaptados pavilhões existentes. 'O problema da habitação', tema abordado no simultâneo Congresso de Arquitetura, foi apresentado num conjunto de três pavilhões temporários adjacentes e interligados. 


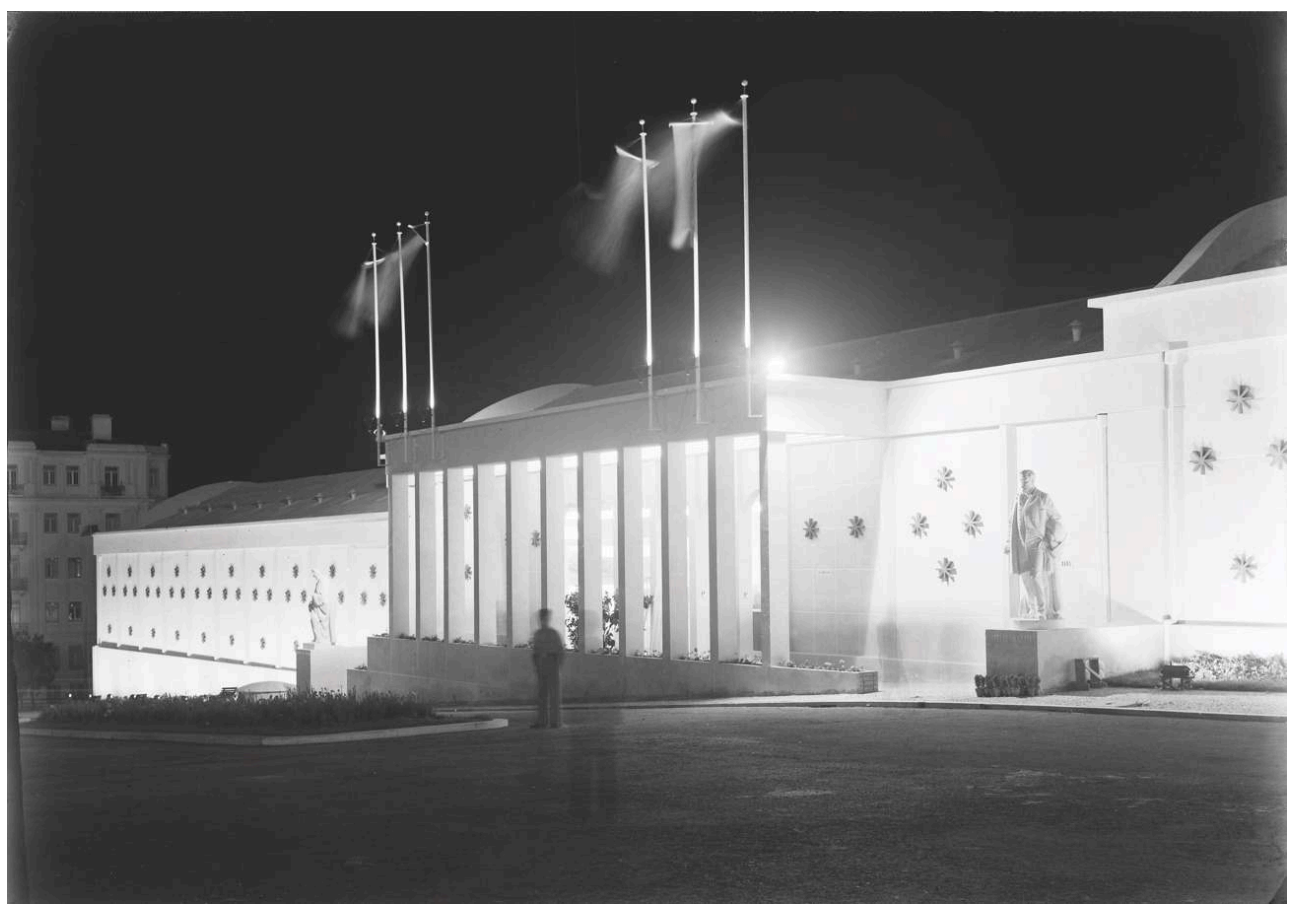

Fig. 3 - Exposição Quinze Anos de Obras Públicas, Pavilhão de Hidráulica, arq. Jorge Segurado, 1948 Fotografia de Mário Novais (c) Col. Estúdio Mário Novais [CFT003.5732] | FCG-Biblioteca de Arte e Arquivos

Em face do pavilhão de Hidráulica, no exterior, existia um espaço ocupado por empresas particulares concessionárias dos grandes aproveitamentos hidroelétricos do país, comportando modelos de barragens com albufeiras numa escala que causaria impacto nos visitantes. Nas imediações, as oitocentistas locomotiva D. Luís e as carruagens da mala posta constituíam elementos históricos que sublinhavam o progresso entretanto alcançado.

No exterior, excetuando as alegorias à Engenharia (Barata Feyo) e à Arquitetura (Álvaro de Brée) especialmente criadas para a exposição e assinalando os congressos paralelos, apresentaram-se modelos em gesso descontextualizados, sem indicação dos locais de destino. Na alameda central, em torno do estudo para a estátua equestre de D. João IV, exposto na Exposição do Mundo Português, figuravam vários navegadores, planeados para a zona circundante à Torre de Belém ${ }^{21}$. Junto às entradas dos pavilhões provisórios estavam as estátuas que viriam a ocupar a Avenida da Liberdade ${ }^{22}$ e o Jardim da Estrela $^{23}$, e, nos nichos laterais, D. João III e D. Dinis, criados por Francisco Franco (1885-1955) para a Cidade Universitária de Coimbra. A escolha da estatuária não foi justificada pelos organizadores, mencionando apenas serem obras significativas. Funcionavam como complemento decorativo e cénico da arquitetura. Apesar da aparente arbitrariedade da seleção e da nítida desvalorização da estatuária neste certame (Abreu 2006, 137-153), as peças acentuam os objetivos de legitimação do regime e das obras públicas, sobretudo sob Pacheco. A estátua de D. João IV evocava a «última obra pública legada pelo ministro», inaugurada três semanas após a sua morte (Costa 2012, 27). Os navegadores ecoavam a mitificação heroica do período das viagens de expansão oficialmente privilegiado. As restantes remetem para a capacidade empreendedora, em Lisboa, capital do Império modernizada, e em Coimbra, onde a obra da Cidade Universitária convocava esforços oficiais (Rosmaninho 2006). 

se apenas projetos realizados ou em vias de conclusão, seguindo um espírito de documentação das obras mais representativas. Alguns edifícios apresentados não sairiam da esfera do projeto, como o Palácio da Cidade para o Parque Eduardo VII, por Keil do Amaral (1910-1975), inviabilizado por motivos políticos (Tostões 1997, 95). Quanto a conteúdos ${ }^{24}$, Christian von Oppen considera não constarem obras públicas de grande envergadura, estando o regime representado através da política urbana, que enquadrava projetos arquitetónicos de menor escala, como habitações e escolas ${ }^{25}$ (Oppen 2019, 183). Embora a questão de ordenamento territorial e urbano à escala nacional tenha orientado a apresentação dos projetos - mapas e fotografias aéreas, comprovando a cobertura territorial, enquadravam os exemplos individuais selecionados -, esta visão é redutora, pois figuraram intencionalmente obras e infraestruturas encaradas como representativas do regime, como o Estádio Nacional, a Barragem Marechal Carmona ou a Cidade Universitária de Coimbra. Salazar salientaria, no encerramento, essa obra «variada e multiforme, de majestosos edifícios ou pequenas habitações graciosas» nascida do "conceito do Governo e da sociedade portuguesa» (Salazar 1948, 248-249).

38 Em adição às salas sobre obras públicas presentes nos pavilhões portugueses das exposições internacionais (Galvão 2003, 362, 371; Lobo e Alves 2017), a exposição de 1940 permitira uma antevisão do discurso expositivo agora empregue: a Sala do Futuro apresentou planos para o desenvolvimento urbano da capital, e os Pavilhões das Telecomunicações, e dos Portos e Caminhos de Ferro integravam modelos de cabines telefónicas e réplicas de novas locomotivas, comprovando o desenvolvimento recente (Acciaiuoli 1998, 163, 184-186).

Atendendo ao carácter sintético pretendido, abundaram gráficos evolutivos e diagramas, que expressavam verbas despendidas e a diferença face aos anos iniciais do regime, num recurso comparativo já empregue na Exposição Documentária de 1934 (Gori 2018a). Complementarmente, o visitante tinha acesso a folhetos desdobráveis, comportando informação sobre a secção, a sua história, dados numéricos, mapas de distribuição e fotografias ${ }^{26}$.

Mapas relevados e luminosos suportavam a ideologia oficial centrada na nação. A inclusão de dados individualizados sobre determinadas regiões, como os planos de urbanização, reforçava o propósito de comprovar a efetividade do alcance territorial, respondendo às acusações dos opositores do regime. Não obstante, a centralidade de Lisboa revelou-se no núcleo individualizado do município, cuja ligação ao Ministério das Obras Públicas fora reforçada pelo impulso de Duarte Pacheco.

41 Dos edifícios e infraestruturas, exibiam-se maquetas, complementadas por fotografias ampliadas de edifícios e vistas aéreas, e plantas de urbanização em grande escala, acompanhadas de legendas curtas, reforçando de modo exaustivo a capacidade construtiva e o incremento do país. Alguns núcleos demonstraram maior arrojo estético na apresentação dos conteúdos: a secção da Administração Geral dos CTT, por exemplo, ao invés de apresentar maquetas singularizadas sobre suportes em torno dos quais o visitante se movimentava, integrou-as em nichos individualizados com espelhos no fundo. Esta secção também se demarcou por incluir alocuções sonoras sobre a sua atividade.

42 A fotografia prestou-se, ademais, a um envolvimento emocional e identificativo, embora mais comedido do que nas montagens da exposição de Paris (Lobo e Alves

MIDAS, 12 | 2020 
2017): a Junta Autónoma de Estradas exibia uma fotografia recortada em tamanho real de um cantoneiro, enaltecendo o papel dos trabalhadores na realização e manutenção das obras públicas. Esta ideia ficava também expressa em gráficos evolutivos da média diária de trabalhadores ocupados em determinado serviço. Recorreu-se, ainda, a fotomontagens comparativas para demonstração da resolução de problemas, como no caso das passagens de nível nas vias férreas, valorizando a ordem e regeneração possibilitada pelo Estado Novo face à desorganização precedente.

Pontualmente, como elemento de dinamização espacial, surgiam pinturas de cariz decorativo, como a Alegoria à História Trágico-Marítima, por Jorge Barradas (1894-1971), no núcleo da Comissão de Obras da Base Naval de Lisboa (fig. 4), e modelos de esculturas que integravam edifícios. Porém, ao contrário do que sucedera na Exposição do Mundo Português e mesmo nas exposições internacionais, a decoração artística não terá constituído uma preocupação central - não se descure que António Ferro não esteve envolvido nesta exposição.

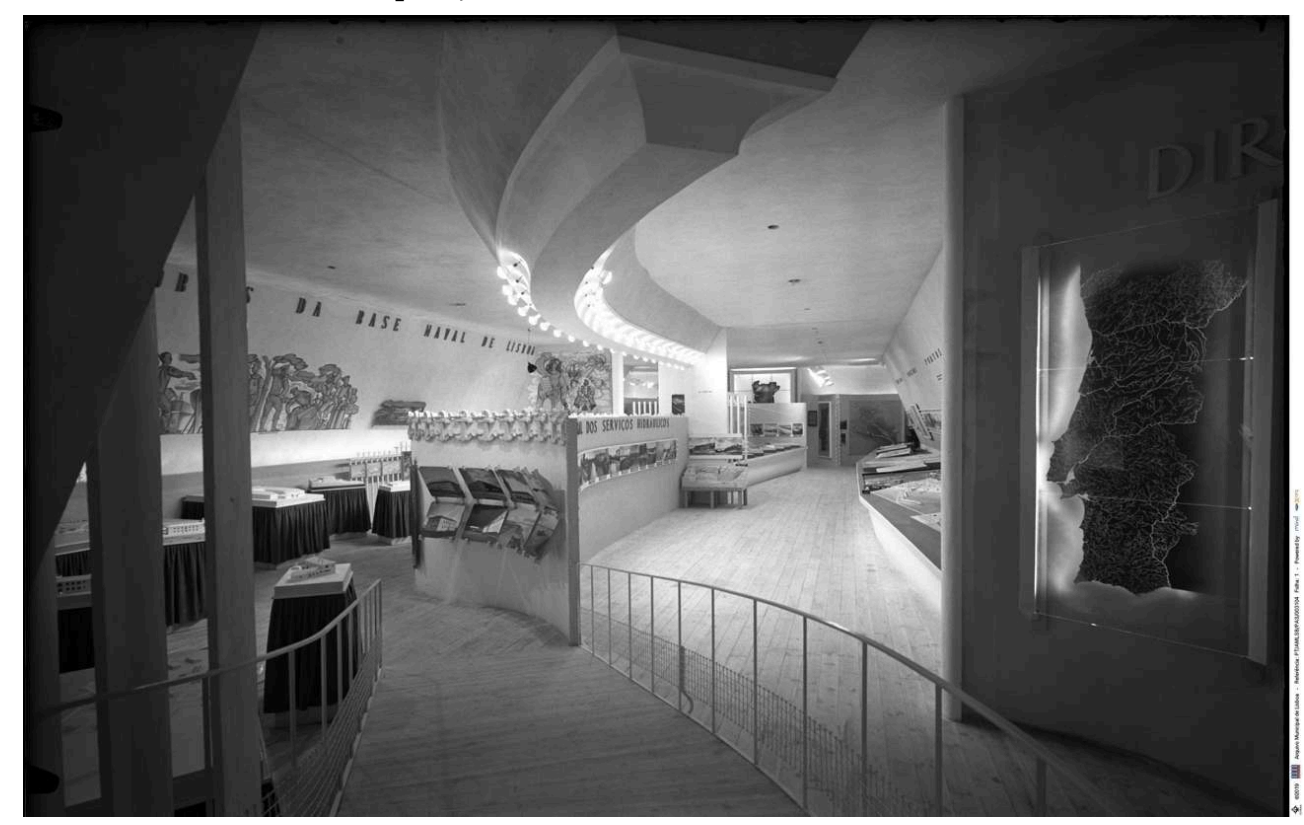

Fig. 4 - Exposição Quinze Anos de Obras Públicas, Secção de Hidráulica, núcleos da Comissão de Obras da Base Naval de Lisboa (lado esq.) e da Direção Geral dos Serviços Hidráulicos (lado dto.), 1948

Fotografia de António Passaporte @ Arquivo Municipal de Lisboa, PT/AMLSB/PAS/003104

Houve espaço para cenários mais elaborados e imersivos, englobando dioramas simulando paisagens pontuadas por obras de engenharia e acompanhadas de modelos, junto dos quais o visitante podia passar sobre uma rampa, ou modelos de habitação em tamanho natural ${ }^{27}$ que era possível atravessar. Estes mecanismos apresentam alguns contornos do que Michael Tymkiw definiu como engaged spectatorship (Tymkiw 2018, 9-10), e que já haviam estado presentes, por exemplo, na exposição de Belém: a entrada na sala Portugal 1940 (Pavilhão dos Portugueses no Mundo), fazia-se por uma rampa semelhante à proa de um navio (Gori 2018b, 712), no Pavilhão dos Portos e Caminhos de Ferro existiam modelos de gruas (Acciaiuoli 1998, 182), e recriaram-se aldeias portuguesas com presença de habitantes (Acciaiuoli 1998, 169-171). Tymkiw atentou em exposições nazis, que, apropriando-se de técnicas desenvolvidas por antigos membros da Bauhaus e pelos construtivistas no contexto expositivo soviético dos anos de 1920, se assumiram como meio de comunicação para as massas e procuraram incentivar os 
visitantes a participar no processo de mudança social e política. Na exposição Gebt mir vier Jahre Zeit (Berlim, 1937), que apresentava o plano quadrienal de Hitler antecedendo a guerra, os visitantes eram convidados a interagir com máquinas industriais em funcionamento (Tymkiw 2018, 138). Não se apurou a possibilidade de manuseamento dos objetos em Lisboa. Não obstante, uma fotografia aquando da visita de Salazar fixou a demonstração do funcionamento de um modelo reduzido de guindaste portuário (fig. 5). Adicionalmente, os trajetos incluíam a exibição de amostras de materiais, equipamentos, e instrumentos de topografia, telegrafia, eletricidade, entre outros, símbolos do investimento na modernização infraestrutural, aproximando o visitante das inovações materiais e tecnológicas (fig. 6).

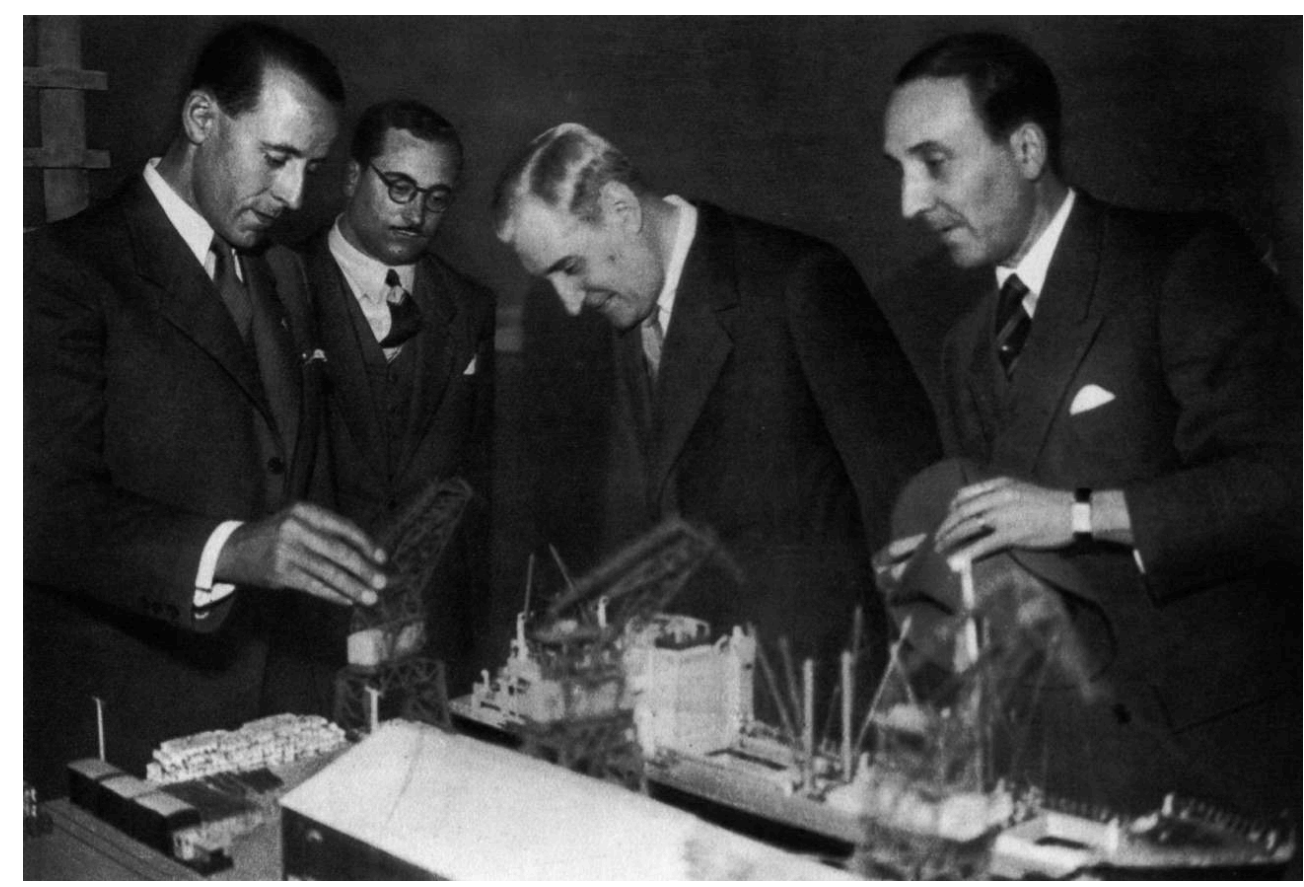

Fig. 5 - Exposição Quinze Anos de Obras Públicas, visita de Salazar, 1948

Fonte: Quinze Anos de Obras Públicas. 1932-1947 (1948) 


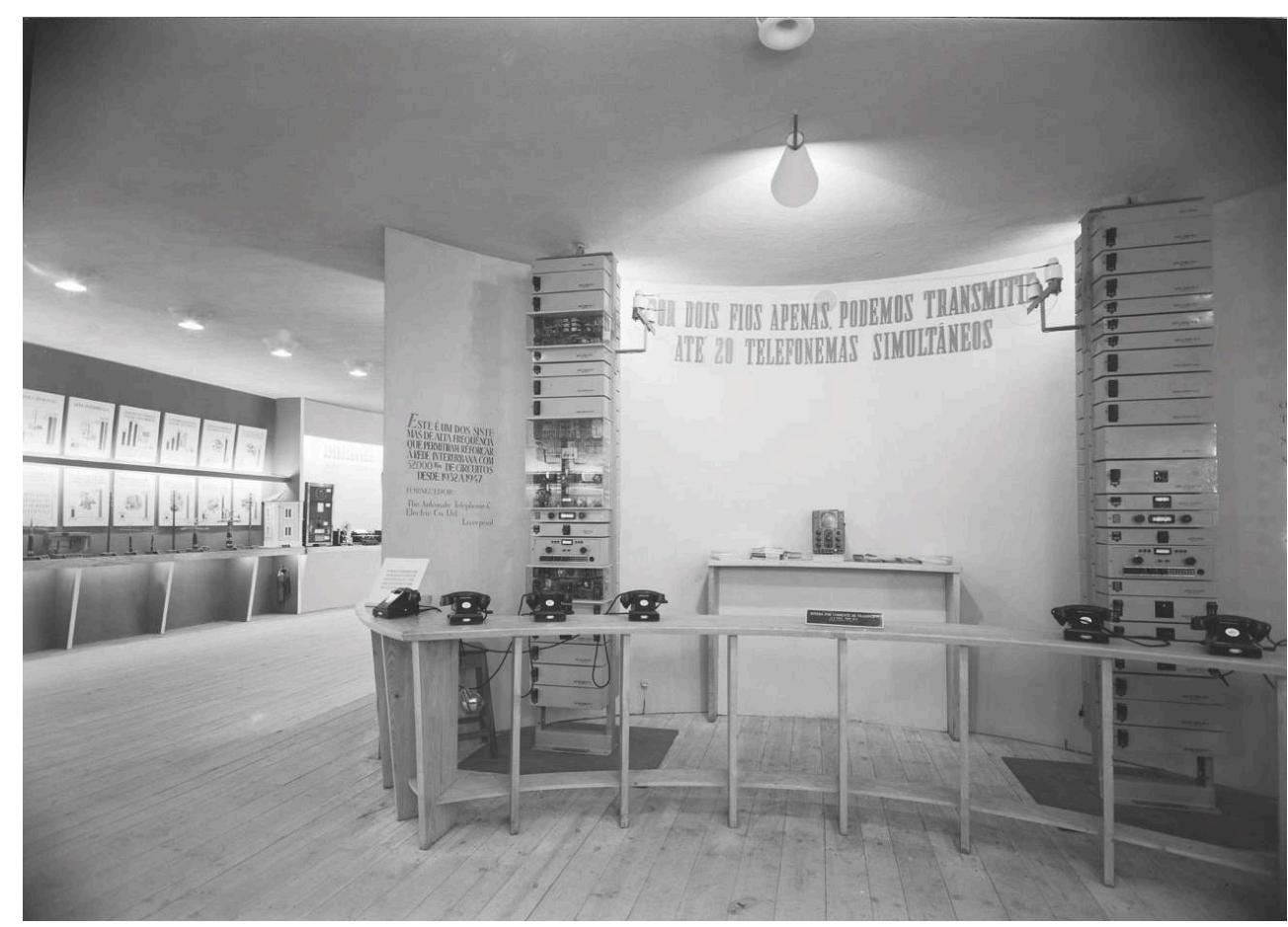

Fig. 6 - Exposição Quinze Anos de Obras Públicas, Secção de Comunicações, núcleo da Administração Geral dos CTT: instalações telefónicas de alta frequência e equipamentos, 1948

Fotografia de Mário Novais ( C Col. Estúdio Mário Novais [CFT003.23083] I FCG-Biblioteca de Arte e Arquivos

O recinto e os edifícios possuíam um forte simbolismo, veiculando a inovação que se procurava sublinhar, mas foram dissimulados no interior. Em termos de organização espacial, privilegiou-se a circulação e o diálogo. Utilizaram-se estruturas expositivas que permitiam observar espaços adjacentes e possibilitavam colocação de objetos e painéis, em alturas e inclinações distintas, e direcionar a iluminação, num percurso que conduzia o público através de uma profusão de empreendimentos públicos encadeados. No geral, predominou um ambiente repetitivo de dinamismo comedido, pautado pela clarividência e pela imagem moldada ao sabor oficial, contrário a manifestações revolucionárias vanguardistas e em conformidade com o espírito conservador do salazarismo - à semelhança da modernidade contida das obras públicas sob Duarte Pacheco (Carvalho 2018), em exibição. Almejava-se que os visitantes ficassem convencidos sem questionar as informações, integrados nos propósitos de condução do país estipulados pelo regime.

O objetivo de fomentar sentimentos de orgulho nacional e pertença entre os visitantes é nítido. Apesar da intenção dominante de impressionar pela magnitude, pela inovação e pelo progresso atingido desde 1932, o recurso à história como fator legitimador do presente, que atingira o expoente na exposição dos Centenários, não foi completamente omitido, ainda que marginalizado. Documentação antiga e estátuas de figuras históricas comunicaram num plano simbólico destacando momentos específicos do passado nacional, e meios de transporte antigos figuraram como contraste às inovações recentes. Prevaleceu uma comunicação demonstrativa e inclusiva, com referências imediatas, sem ambientes metafóricos ou analogias complexas apreensíveis somente por um público mais erudito, pelo que temos relutância em classificá-la como "exposição multilinguagem" (Gori 2018b). 
47 A abrangência de um público diversificado verificou-se nas cerimónias oficiais e na inclusão de momentos recreativos, como animação noturna com concertos e restaurante, tendo-se investido na publicitação extensa na imprensa ${ }^{28}$, no convite a funcionários públicos e empresas (Andrade 1948), e na organização de vastas excursões de operários e estudantes vindos de diversos pontos do país (Anónimo 1948a).

Salazar visitou a exposição quatro vezes, participando na sessão de encerramento. Nessa ocasião, a satisfação oficial com a iniciativa ficou plasmada no discurso de Ulrich, que, desejando realizar uma segunda edição, lamentava «não ser possível manter indefinidamente a Exposição, acrescentando-lhe dia a dia os novos melhoramentos que vão surgindo por esse país fora» (Ulrich 1948b, 240).

\section{Considerações finais}

49 Num período definido por crises internas e pela necessidade de posicionar favoravelmente o Estado Novo no cenário internacional, a exposição Quinze Anos de Obras Públicas revestiu-se de um papel político inequívoco. Na esteira do exhibitionary complex definido por Tony Bennett, intentou-se que a sociedade se relacionasse com as instituições detentoras do poder e entendesse o progresso material como um feito coletivo nacional (Bennett 1988, 79-80). Tal ficou explícito no discurso proferido por Marcelo Caetano, dirigindo-se abertamente aos adversários:

Hão-de pois continuar a dizer que o Estado Novo é um regime governado em proveito de uma classe ou de um grupo, e que descurou o nível de vida do povo português. Debalde nós procuraremos pegar-lhes nas mãos e trazê-los aqui, a ver esta pequena parcela do esforço produzido, para, em presença do conjunto das estradas, dos portos, das barragens para irrigação e para produção de electricidade, das escolas, dos hospitais, dos quartéis, das casas económicas e de tudo o mais que nestes pavilhões se ostenta, lhes podermos perguntar [...] se esta obra não é uma obra eminentemente e desinteressadamente nacional com cuja realização nunca se procurou captar votos e antes muitas vezes se sacrificaram interesses de partidários e adeptos. (Caetano 1948, 207-208)

50 A exposição alicerçou-se numa apresentação panorâmica, mas abrangente e repetitiva, dos empreendimentos construídos e planeados no passado recente, estrategicamente delineada segundo um espírito teleológico para gerar consenso sobre a ação oficial e, assim, legitimar a continuidade do regime no presente e no futuro.

51 Numa linha propagandística idêntica às exposições sob impulso de Hitler e Franco ilustrando a temática das obras públicas, a exposição de 1948 demarcou-se, porém, desses certames pelas evidências estatísticas do progresso, pelo elogio pontual da Nação que suportava o empreendimento, bem como pela integração de um design expositivo menos académico, compassado com o grafismo modernista das exposições internacionais dos anos de 1930. Tal foi atingido pela organização por parte de figuras ligadas ao governo e à política de propaganda, e pela contratação de decoradores com experiência nessa encenação, sem integração de artistas comprovadamente avessos ao regime, mantendo uma fórmula confirmada e desenvolvendo exaustivamente alusões de progresso presentes em certames anteriores. A exposição convocou, de forma implícita, uma personagem do passado recente, decisiva no impulso modernizador das obras públicas, assim estabelecendo uma genealogia legitimadora da continuidade. A aposta oficial na engenharia e na industrialização que ficou expressa na exposição não implicou um abandono total do uso público da história para legitimação do regime. A 
exposição espelhou, pois, a linha de ação propagandística determinada para subsistência do regime no pós-guerra, que procurou evidenciar os feitos concretizados e rememorar as datas significativas e mitificadas, estratégia repetida de forma relativamente acrítica após a saída de cena de António Ferro (ó 1999, 225).

Agradecimentos

Esta investigação foi realizada no âmbito da bolsa de doutoramento financiada pela Fundação para a Ciência e a Tecnologia (SFRH/BD/139172/2018), comparticipada pelo Fundo Social Europeu e por fundos do MCTES. A autora agradece a permissão de reprodução de fotografias ao Arquivo Municipal de Lisboa - Fotográfico e à Biblioteca de Arte da Fundação Calouste Gulbenkian, e aos revisores pelas críticas e sugestões.

\section{BIBLIOGRAFIA}

“Comissão Executiva da Exposição de Obras Públicas." 1948. Arquivo Nacional da Torre do Tombo (ANTT), Fundo ISBA, cx. 271, proc. 90.

“Comissão Executiva da Exposição de Obras Públicas." 1948. Guia da Exposição de Obras Públicas. Lisboa: Soc. Astória.

“Curriculum Vitae.” 1946. Arquivo Contemporâneo do Ministério das Finanças, Fundo Direção Geral da Fazenda Pública, Processos individuais de funcionários, cx. 11, 16.05.1946.

"Processo de Mário Costa Ferreira Lima." s/d. Arquivo Contemporâneo do Ministério das Finanças, Fundo Direção Geral da Contabilidade Pública, Cadastro de Pessoal, pt. 28.

“Processo Individual: Eduardo Rodrigues de Carvalho." 1933-1954. Biblioteca e Arquivo Histórico da Economia, Acervo Infraestruturas, Transportes e Comunicações, PI-CX 33.

Abreu, José Guilherme de. 2006. “Escultura Pública e Monumentalidade em Portugal (1948-1998): Estudo Transdisciplinar de História da Arte e Fenomenologia Genética.” Tese de doutoramento em História da Arte, Universidade Nova de Lisboa.

Acciaiuoli, Margarida. 1991. “Os Anos 40 em Portugal: O País, o Regime, e as Artes. «Restauração» e «Celebração»." Vol. 1. Tese de doutoramento em História da Arte, Universidade Nova de Lisboa.

Acciaiuoli, Margarida. 1998. Exposições do Estado Novo. 1934-1940. Lisboa: Livros Horizonte.

Andrade, Mário de. 1948. “Ofício para o Inspetor Superior das Bibliotecas e Arquivos”, 08.07.1948. Arquivo Nacional da Torre do Tombo (ANTT), Fundo ISBA, cx. 269, proc. 12.

Anónimo. 1948a. “Algumas Efemérides da Exposição de Obras Públicas.” In Quinze Anos de Obras Públicas. 1932-1947, vol. II - Exposição e Congressos de Engenharia e de Arquitectura, ed. Comissão Executiva da Exposição de Obras Públicas, 199-225. Lisboa: Imprensa Nacional.

Anónimo. 1948b. “Sessão Solene de Encerramento.” In Quinze Anos de Obras Públicas. 1932-1947, vol. II - Exposição e Congressos de Engenharia e de Arquitectura, ed. Comissão Executiva da Exposição de Obras Públicas, 239-249. Lisboa: Imprensa Nacional. 
Anónimo. 1948c. “Edifício Central.” In Quinze Anos de Obras Públicas. 1932-1947, vol. II - Exposição e Congressos de Engenharia e de Arquitectura, ed. Comissão Executiva da Exposição de Obras Públicas, 39-53. Lisboa: Imprensa Nacional.

Anónimo. 1948d. Imprensa. In Quinze Anos de Obras Públicas. 1932-1947, vol. II - Exposição e Congressos de Engenharia e de Arquitectura, ed. Comissão Executiva da Exposição de Obras Públicas, 226-235. Lisboa: Imprensa Nacional.

Basilio, Miriam M. 2013. Visual Propaganda, Exhibitions, and the Spanish Civil War. Farnham: Ashgate. Benjamin, Walter. 2012. “A Obra de Arte na Era da sua Reprodutibilidade Técnica.” In Sobre Arte, Técnica, Linguagem e Política, 59-95. Lisboa: Relógio d'Água.

Bennett, Tony. 1988. The Exhibitionary Complex. New Formations. 4: 73-102.

Borges, José. 2010. “Eduardo Anahory. Percurso de um Designer de Arquitectura.” Dissertação de Mestrado em Arquitetura, Instituto Superior Técnico.

Brites, Joana. 2015. "Power and Architecture in Portuguese Fascism: Political and Artistic Control and Resistance." Journalism and Mass Communication 5 (7): 360-371.

Brites, Joana. 2017. “Estado Novo, Arquitetura e "Renascimento Nacional." Risco: Revista de Pesquisa em Arquitetura e Urbanismo 15 (1): 100-113.

Caetano, Marcelo. 1948. "O Significado Político da Exposição Definido num Discurso do Prof. Doutor Marcelo Caetano, Presidente da Comissão Executiva da União Nacional.” In Quinze Anos de Obras Públicas. 1932-1947, vol. II - Exposição e Congressos de Engenharia e de Arquitectura, ed. Comissão Executiva da Exposição de Obras Públicas, 207-209. Lisboa: Imprensa Nacional.

Carvalho, Eduardo Rodrigues de. 1948a. “A Exposição de Obras Públicas.” In Quinze Anos de Obras Públicas. 1932-1947, vol. I - Livro de Ouro, ed. Comissão Executiva da Exposição de Obras Públicas, 19-24. Lisboa: Imprensa Nacional.

Carvalho, Eduardo Rodrigues de. 1948b. "Discurso do Presidente da Comissão Executiva da Exposição de Obras Públicas.” In Quinze Anos de Obras Públicas. 1932-1947, vol. II - Exposição e Congressos de Engenharia e de Arquitectura, ed. Comissão Executiva da Exposição de Obras Públicas, 20-25. Lisboa: Imprensa Nacional.

Carvalho, Rita Almeida. 2018. “Ideology and Architecture in the Portuguese 'Estado Novo': Cultural Innovation within a Para-Fascist State (1932-1945)." Fascism 7 (2): 141-174.

Corkil, David, e José Carlos Pina Almeida. 2009. “Commemoration and Propaganda in Salazar's Portugal: The ‘Mundo Português' Exposition of 1940. Journal of Contemporary History 44 (3): 381-399.

Costa, Sandra Vaz. 2012. o País a Régua e Esquadro. Urbanismo, Arquitectura e Memória na Obra Pública de Duarte Pacheco. Lisboa: IST Press.

Coutinho, Bárbara, ed. 2017. José Espinho: Vida e Obra. Casal de Cambra: Caleidoscópio.

Cunha, Luís. 1994. “A Nação nas Malhas da sua Identidade: O Estado Novo e a Construção da Identidade Nacional.” Provas de aptidão pedagógica, Universidade do Minho.

Dirección General de Arquitetura. 1942. Revista Nacional de Arquitectura, 10-11.

Fernández, Celso Almuiña. 2000. "Franco y Salazar, dos Dictadores em Busca de Reconocimiento (1942/1949)." In Relações Portugal e Espanha: Cooperação e Identidade, Fernando de Sousa et al., 123-164. Porto: CEPESE/FRAH. 
Ferreira, Fátima Moura. 2019. “O Estado Novo através do País: Obras Públicas e Imagética Discursiva, entre a Perenidade e a Hibridez." In Representações do Poder do Estado em Portugal e no Império, ed. Fátima Moura Ferreira e Eduardo Fernandes, 24-46. s.1.: Circo de Ideias.

França, José-Augusto. 1991. A Arte em Portugal no Século XX. 3. ${ }^{\mathrm{a}}$ ed. Venda Nova: Bertrand.

França, José-Augusto. 2012. O Ano XX: Lisboa 1946. Estudos de Factos Socioculturais. Lisboa: Imprensa Nacional Casa da Moeda.

Galvão, Andreia. 2003. "O Caminho da Modernidade: A Travessia Portuguesa, ou o caso da Obra de Jorge Segurado como um exemplo de Complexidade e Contradição na Arquitectura, 1920-1940." Vol. I. Tese de doutoramento, Universidade Lusíada.

Gentile, Emilio. 1996. The Sacralization of Politics in Fascista Italy. Cambridge: Harvard University Press.

Gori, Annarita. 2018a. “A Laboratory for Propaganda: Estado Novo Political Exhibitions (1934-1940)." In New Journeys in Iberian Studies: a (trans-)national and (trans)regional Exploration, Mark Gant, Paco Ruzzante \& Anneliese Hatton, 116-136. Newcastle: Cambridge Scholars Publishings.

Gori, Annarita. 2018b. "Celebrate Nation, Commemorate History, Embody the Estado Novo: The Exhibition of the Portuguese World (1940)." Cultural and Social History. 15(5): 699-722.

Klonk, Charlotte. 2009. Spaces of Experience: Art Gallery Interiors from 1800 to 2000. London/New Haven: Yale University Press.

Lira, Sérgio. 2002. Museums and Temporary Exhibitions as Means of Propaganda: The Portuguese Case during the Estado Novo. PhD, Department of Museum Studies, University of Leicester.

Lobo, Paula Ribeiro, e Margarida Brito Alves. 2017. “Espaço, Fotografia e 'Factografia' na Propaganda do SPN. Comunicação Pública 12 (23).

Manaças, Vitor. 2005. "Percursos do Design em Portugal." Vol. I. Tese de doutoramento em Belas Artes (Design de Equipamento), Faculdade de Belas Artes da Universidade de Lisboa.

Matos, Helena. 2010. Salazar. A Propaganda, 1934-1938. Lisboa: Temas e Debates.

Mosse, George. 1975. The Nationalization of the Masses: Political Symbolism and Mass Movements in Germany from the Napoleonic Wars Through the Third Reich. Ithaca: Cornell University Press.

Mosteiro, Javier García-Gutierrez. 2003. "El Regionalismo y la Dirección General de Regiones Devastadas.” In Um Siglo de Vivenda Social: 1903-2003, ed. Carlo Sambricio, 255-258. Madrid: Ministerio de Fomento.

Moura, Antonieta. 1948. “A Exposição de Obras Públicas." Panorama. Revista Portuguesa de Arte e Turismo 35: s/p.

Neto, Teresa. 2016. “Arquitecturas Expositivas e Identidade Nacional: Os Pavilhões de Portugal em Exposições Internacionais entre a Primeira República e o Estado Novo.” Dissertação de Mestrado em Arquitetura, Instituto Superior Técnico.

Nunes, Ana, e José Brandão de Brito. 1992. "Política Económica, Industrialização e Crescimento.” In Nova História de Portugal, vol. XII: Portugal e o Estado Novo (1930-1960), coord. Fernando Rosas, 306-351. Lisboa: Editorial Presença.

Ó, Jorge Ramos do. 1999. Os Anos de Ferro: O Dispositivo Cultural Durante a "Política do Espírito" 1933-1949. Lisboa: Editorial Estampa. 
Oppen. Christian von. 2019. "Portugal's Urban Design under the Estado Novo: Foreign Influences before and after the Second World War." In Representações do Poder do Estado em Portugal e no Império, ed. Fátima Moura Ferreira e Eduardo Fernandes, 179-186. s.l.: Circo de Ideias.

Ortuño, Carla Ruesga. 2016. “Arquitectura, Estética e Ideología en Reconstrucción: La Obra de la Dirección General de Regiones Devastadas (1939-1953).” Dissertação de mestrado de Estudios Avanzados en Historia del Arte, Universitat de Barcelona.

Pohlmann, Ulrich. 1999. “El Lissitzky’s Exhibition Designs: The Influence of his Work in Germany, Italy, and the United States, 1923-1943." In El Lissitzky. Beyond the Abstract Cabinet: Photography, Design, Collaboration, ed. Margarita Tupitsyn, 52-64. Barcelona: Museu d'Art Contemporani de Barcelona.

Portas, Nuno. 2008. “A Evolução da Arquitectura Moderna em Portugal: Uma Interpretação.” In A Arquitectura para Hoje, 149-210. Lisboa: Livros Horizonte.

Quintas, Ana. 2014. “Grafismo e Ilustração em Portugal nos Anos 40.” Tese de doutoramento em História da Arte, Universidade Nova de Lisboa.

Quinze Anos de Obras Públicas. 1932-1947. 1948. Vol. II - Exposição e Congressos de Engenharia e de Arquitectura, ed. Comissão Executiva da Exposição de Obras Públicas. Lisboa: Imprensa Nacional.

Ramos, Fernando Guillermo Vázquez. 2017. "Exposições de Arquitetura: Cronologia de um Fenômeno Cultural Moderno e Algumas Inquietações.” arq.urb 20: 8-21.

Reis, Bruno C. 2015. “A Vida Política.” In História Contemporânea de Portugal: 1808-2010, vol. 4, coord. José Luís Cardoso, 33-71. Carnaxide: Objectiva.

Rezola, Maria Inácia. 2008. “The Franco-Salazar Meetings: Foreign Policy and Iberian Relations During the Dictatorships (1942-1963).” e-JPH 6 (2): 58-68.

Ribeiro, Ana Isabel. 1993. “Arquitectos Portugueses: 90 Anos de Vida Associativa. 1863-1953.” Vol. I. Dissertação de mestrado em História da Arte Contemporânea, Universidade Nova de Lisboa.

Ribeiro, Ana Isabel. 2008. "Relembrando o Congresso de 48." I Congresso Nacional de Arquitectura [edição fac-similada], coord. Ana Tostões, 23-33. Lisboa: Ordem dos Arquitectos.

Rollo, Maria Fernanda. 2007. Portugal e a Reconstrução Económica no Pós-Guerra. O Plano Marshall e a Economia Portuguesa nos Anos 50. Lisboa: Ministério dos Negócios Estrangeiros.

Rosas, Fernando. 1994. "Sob os Ventos da Guerra: A Primeira Crise Séria do Regime (1940-1949)." In História de Portugal, dir. J. Mattoso, vol. 7 - O Estado Novo (1926-1974), 301-415. Lisboa: Círculo de Leitores.

Rosas, Fernando. 2013. Salazar e o Poder. A Arte de Saber Durar. Lisboa: Tinta-da-China.

Rosmaninho, Nuno. 2006. O Poder da Arte. O Estado Novo e a Cidade Universitária de Coimbra. Coimbra: Imprensa da Universidade.

Salazar, António Oliveira. 1948. "Discurso do Senhor Presidente do Conselho." In Quinze Anos de Obras Públicas. 1932-1947, vol. II - Exposição e Congressos de Engenharia e de Arquitectura, ed. Comissão Executiva da Exposição de Obras Públicas, 248-249. Lisboa: Imprensa Nacional.

Salazar, António Oliveira. 1951. “Votar é um Grande Dever (07.10.1945).” In Discursos e Notas Políticas, vol. IV, 169-191. Coimbra: Coimbra Editora.

Santos, Pedro Pavão dos. 2009. "Jorge Segurado: Um Arquiteto Moderno de Casas e Sonhos na República, Ditadura Militar e Estado Novo.” Vol.1. Dissertação de mestrado, Universidade Nova de Lisboa. 
Santos, Rui Afonso. 1994. O Design e a Decoração em Portugal - Exposições e Feiras: Os Anos Vinte e Trinta. Vol. I. Dissertação de mestrado em História da Arte Contemporânea, Universidade Nova de Lisboa.

Schnapp, Jeffrey T. 2007. “Mostre.” In Kunst und Propaganda im Streit der Nationen 1930-1945, ed. Hans-Jorg Czech \& Nikola Doll, 78-87. Dresden: Sandstein Verlag.

Segurado, Jorge. 1940. Sinfonia do Degrau. Impressões de New York e de outras Terras dos Estados Unidos da América do Norte. Lisboa: Soc. Nac. Tipografia.

Segurado, Jorge. 1948. "Elementos Artísticos e Condições de Realização da Exposição de Obras Públicas.” In Quinze Anos de Obras Públicas. 1932-1947, vol. II - Exposição e Congressos de Engenharia e de Arquitectura, ed. Comissão Executiva da Exposição de Obras Públicas, 182-184. Lisboa: Imprensa Nacional.

Serra, Filomena, e João Parreira. 2017. "Usos e Funções da Fotografia Impressa na Exposição Documentária do I Congresso da União Nacional (1934).” Comunicação Pública 12 (23).

Silva, Filipa Ribeiro. 2004. “Carvalho, Eduardo Rodrigues de.” In Dicionário Biográfico Parlamentar. 1935-1974, vol. I, dir. Manuel Braga da Cruz, António Costa Pinto, 365-36. Lisboa: Imprensa de Ciências Sociais/Assembleia da República.

Souto, Helena. 1993. "Notas Biográficas." In Frederico George. Ver pelo Desenho, 45-52. Lisboa: Câmara Municipal de Lisboa.

Stone, Marla. 1998. The Patron State: Culture \& Politics in Fascist Italy. Princeton: Princeton University Press.

Telmo, Cottinelli. 1941. “A Exposição Nova Arquitectura Alemã.” Acção, 13.11.1941: 5.

Tostões, Ana. 1997. Os Verdes Anos na Arquitetura Portuguesa dos Anos 50. 2. ed. Porto: FAUP Publicações.

Tymkiw, Michael. 2018. Nazi Exhibition Design and Modernism. Minneapolis/London: University of Minnesota Press.

Ulrich, José Frederico. 1948a. “Abertura.” In Quinze Anos de Obras Públicas. 1932-1947, vol. I - Livro de Ouro, ed. Comissão Executiva da Exposição de Obras Públicas, 17-18. Lisboa: Imprensa Nacional.

Ulrich, José Frederico. 1948b. “Sessão de Encerramento." In Quinze Anos de Obras Públicas. 19321947, vol. II - Exposição e Congressos de Engenharia e de Arquitectura, ed. Comissão Executiva da Exposição de Obras Públicas, 239-243. Lisboa: Imprensa Nacional.

Zech, Ulrike. 2005. Die nationalsozialistische Wanderausstellung Neue Deutsche Baukunst und ihre Rezeption in Portugal (1941). Dissertação de mestrado, Technische Universität Berlin.

\section{NOTAS}

1. Neste contexto, a defesa da arquitetura imbuída dos valores do Movimento Moderno tornou-se uma questão política, refletindo-se na produção arquitetónica da década seguinte (Tostões 1997, 33-46).

2. A consulta do espólio do arquiteto Jorge Segurado não foi possível devido ao empacotamento da documentação decorrente de obras no edifício da Academia Nacional de Belas-Artes, que inviabilizou o acesso a investigadores.

3. Decreto n..$^{36277}$, de 14.05.1947. Diário do Governo, série I, n.ำ 109, 14.05.1947, p. 418. 
4. Na sessão inaugural da primeira exposição itinerante (Madrid, 1940) esteve um representante do embaixador português, identificado como Senhor Boaventura (Ortuño 2016, 73).

5. Decreto-Lei n.․ 36061, de 27.12.1946. Diário do Governo, série I, n.ํ295, 27.12.1946, pp. 1315-1316.

6. Decreto-Lei n.․ 36575, de 04.11.1947. Diário do Governo, série I, n.․ 256, 04.11.1947, pp. 1098-1101.

7. Não havendo aqui espaço para desenvolver este assunto, refira-se que as personalidades e grupos profissionais que visitaram a exposição representaram os pilares que, segundo Fernando Rosas, permitiram a continuidade do salazarismo no pós-guerra (Rosas 2013, 185-352).

8. Mário Lima foi chefe de secção na Direção Geral de Contabilidade Pública, aposentado em 1945 ("Processo de Mário Costa Ferreira Lima" s/d).

9. Informações sobre o percurso profissional de Rodrigues de Carvalho recolhidas no seu processo individual do Ministério das Obras Públicas ("Processo Individual" 1933-1954; Silva 2004).

10. Integrou a comissão da Grande Exposição Industrial Portuguesa (1932) (Santos 1994, 116; Santos 2009, 292-294), participou na Feira Popular, nas feiras no Campo Grande e na decoração das comemorações do Centenário da Tomada de Lisboa aos Mouros, 1947 (Galvão 2003, 345-356; Santos 2009, 340-341).

11. Exposição Universal de Paris (1937: assistente técnico do Pavilhão de Portugal); Feira Mundial de Nova Iorque e Exposição Internacional Golden Gate em S. Francisco (1939, convite direto sem concurso); Exposição de Arte Popular em Madrid (1943).

12. Formado em Ciências Histórico-Filosóficas e como bibliotecário-arquivista, iniciou a carreira como conservador do Arquivo Histórico do Ministério das Finanças e viria a ser diretor da Biblioteca Nacional.

13. Kradolfer e Botelho integraram a Exposição Documentária (1934) e participaram nas exposições internacionais em Paris e nos EUA (Acciauioli 1998 16, 48, 89), acrescendo Anahory ao grupo no último destino (Borges 2010, 31-33). Anahory e Araújo participaram nos concursos de ilustração gráfica para cartazes, emblemas e capas de publicações para a Exposição do Mundo Português (Manaças 2005, 97; Borges 2010, 35-36).

14. Formado em Pintura e em Arquitetura, colaborara na decoração pictórica da Exposição do Mundo Português, e participaria nas representações portuguesas nas exposições do IV Centenário da Cidade de São Paulo (1954) e Internacional de Bruxelas (1958), e na exposição comemorativa do V Centenário do Infante D. Henrique (1960, Lisboa), entre outras (Souto 1993). George foi mentor da primeira geração de designers portugueses, que incluiu nomes como Daciano da Costa e Sena da Silva (Manaças 2005, 120).

15. Autodidata, trabalhava como ilustrador e projetista para a Câmara Municipal de Lisboa desde 1935, destacando-se no grafismo de diversas publicações e participando na realização das marchas populares. Na década de 1940 participou na decoração de interiores de hotéis e casas privadas, e passou pelo ateliê de Keil do Amaral, com o qual colaborou na remodelação do Campo Grande. Espinho ficou sobretudo conhecido pela sua longa colaboração como projetista e consultor da fábrica de móveis Olaio, que realizou muitas encomendas para edifícios patrocinados pelo Governo (Coutinho 2017).

16. À semelhança do que Jorge Segurado advogara para as exposições que supervisionou nos EUA (Segurado 1940, 116).

17. Este trabalho estendeu-se à elaboração de propostas de cartazes para a exposição (Quintas 2014, 249-254).

18. Esta exposição, com diversas secções encadeadas, incluiu projetos arquitetónicos e urbanísticos, modelos de habitações à escala real, mapas e fotografias, dados estatísticos e inscrições parietais, bem como divulgou materiais e técnicas de construção (Klonk 2009, 108-113; Santos 2009, 85-86; Ramos 2017, 11-12), integrando também secções experimentais com discursos racionais e condução sensorial dos visitantes. 
19. Zech refere a assunção deste propósito nas exposições nazis, estando patente numa publicação propagandística oficial de 1938 sobre a evolução do caráter das exposições (Zech 2005, 48). Presumivelmente, esta noção foi transversal às restantes exposições políticas realizadas na época.

20. Disponível em: http://www.cinemateca.pt/cinemateca-digital/Ficha.aspx? obraid=1383\&type=Video (consultado a 28 de setembro de 2019).

21. Plano de urbanização, não concretizado, de Cottinelli Telmo (1943): Pedro de Escobar e Pêro de Alenquer (Leopoldo de Almeida); Pedro de Sintra e Diogo Gomes (Álvaro de Brée); Gonçalves Zarco, Nuno Tristão, Gil Eanes e Gaspar Corte-Real (Canto da Maia).

22. Estátuas de Alexandre Herculano e de Almeida Garrett (Barata Feyo), e de Oliveira Martins (Leopoldo de Almeida).

23. Antero de Quental (Barata Feyo).

24. Para uma apresentação mais exaustiva dos conteúdos veja-se Acciaiuoli (1991, 477-484).

25. O autor aproxima a exposição de 1948 a uma exposição de urbanismo britânico ocorrida em Lisboa, em 1941, que pouca influência terá tido junto dos portugueses (Oppen 2019, 183).

26. Foram publicados 35 folhetos distintos, com tiragem de cerca de 50.000 exemplares cada. Em termos estéticos, o grafismo espelhava alguma heterogeneidade por cada secção ter a seu cargo artistas específicos, apesar da presença generalizada da dicotomia caos (passado) versus ordem (presente).

27. Também as citadas exposições itinerantes espanholas incorporaram modelos de habitação à escala natural (Ortuño 2016).

28. Entre maio e dezembro, foram publicados 245 artigos em periódicos nacionais e regionais, listados no livro oficial da exposição (Anónimo 1948d).

\section{RESUMOS}

A exposição Quinze Anos de Obras Públicas (1932-1947), decorrida por empenho oficial em Lisboa, em 1948, apresentou o progresso alcançado no domínio das obras públicas e comunicações desde 1932. Realizada num contexto de legitimação do Estado Novo como regime moderno e socialmente empenhado no pós-guerra, a exposição enquadrou-se numa lógica de recuperação e adaptação de estratégias propagandísticas empregues na década de 1930. Neste artigo, consideramos tratar-se de uma exposição política que funcionou como mecanismo de suporte da permanência do regime, com afinidades conceptuais com certames de temática similar realizados sob Hitler e Franco. Através do cruzamento de fontes e bibliografia, e comparando a exposição de 1948 com exposições oficiais portuguesas anteriores, são analisados dois aspetos pouco explorados pela historiografia: o recurso a uma comissão executiva próxima do Governo e a decoradores com atividade comprovada e coadunada com a estética oficial, e o emprego de uma linguagem expositiva já testada anteriormente, embora relegando o papel simbólico das artes plásticas para um plano secundário. Argumenta-se que tais fatores contribuíram para sustentar o objetivo da exposição de transmissão de sentimentos de pertença coletiva como o combate a movimentos oposicionistas, através da tónica no progresso infraestrutural a nível nacional, fundamento da estratégia de melhoramentos rurais então lançada, e no triunfo da regeneração proporcionada pelo regime sobre a decadência prévia. 
The exhibition Quinze Anos de Obras Públicas (1932-1947) (Fifteen Years of Public Works) was officially promoted in 1948, at the Instituto Superior Técnico in Lisbon, presenting the progress made in the field of public works and communications since 1932. The exhibition occurred within the post-war context of legitimizing the Estado Novo dictatorship as modern and socially engaged, being framed within the recuperation and adaptation of 1930s propaganda strategies. In this paper, this exhibition is considered as a political exhibition, which acted as a support mechanism of the regime's permanence. It is argued that it has conceptual similarities with exhibitions with identic themes promoted under Hitler and Franco. Two aspects relatively underexplored by historiography are analysed, through crossing of sources and bibliography and comparing with previous Portuguese political exhibitions: the resort to an executive committee close to the Government and to decorators with verified experience in line with official aesthetics, and the use of a previously tested exhibition language, though relegating the symbolic role of visual arts to a secondary plan. It is argued that these factors contributed to support the exhibition's goal of transmitting feelings of collective belonging as combat to opposition movements, by highlighting the national-wide infrastructural progress (seen as the foundation of the then established rural improvement strategy) and the triumph of the regeneration obtained due to the regime's action over the prior decadence.

\section{ÍNDICE}

Palavras-chave: exposição temporária, história das exposições, Estado Novo, identidade nacional, exposições e propaganda

Keywords: temporary exhibition, history of exhibitions, Estado Novo, national identity, exhibitions and visual propaganda

\section{AUTOR}

\section{ANA MEHNERT PASCOAL}

É doutoranda em História da Arte na Faculdade de Letras da Universidade de Lisboa e investigadora no ARTIS - Instituto de História da Arte, com bolsa da Fundação para a Ciência e a Tecnologia. Mestre em Arte, Património e Teoria do Restauro (2011) e licenciada em História da Arte (2008) pela mesma Universidade. Foi bolseira de investigação no projeto CuCa_Re: Cure and Care_the Rehabilitation (PTDC/ATP-AQI/2577/2014) (2017-2018) e bolseira BGCT (Bolsa de Gestão de Ciência e Tecnologia) no Museu Nacional de História Natural e da Ciência - Universidade de Lisboa (2011-2017). Integrou as Comemorações do Centenário da Universidade de Lisboa (2010-2011). Tem desenvolvido investigação sobre património cultural, focando relações entre poder, arquitetura e arte no século XX, particularmente durante o Estado Novo.

ARTIS - Instituto de História da Arte, Faculdade de Letras da Universidade de Lisboa, Alameda da Universidade, 1600-214 Lisboa, Portugal, anapascoal@campus.ul.pt 